
Stratocumulus-Topped Marine Boundary Layer and Comparisons with Measurements

andrew S. Ackerman, Owen B. Toon, ‘ and Peter V. Hobbs 


\title{
A Model for Particle Microphysics, Turbulent Mixing, and Radiative Transfer in the Stratocumulus-Topped Marine Boundary Layer and Comparisons with Measurements
}

\author{
Andrew S. Ackerman, ${ }^{*}$ Owen B. Toon,${ }^{*}$ and Peter V. Hobbs* \\ *Atmospheric Sciences, University of Washington, Seatte, Washington \\ ** Space Science Division. NASA Ames Research Center, Moffett Field, California
}

(Manuscript received 16 November 1993, in tinal form 29 September 1994)

\begin{abstract}
A detailed ID model of the stratocumulus-topped marine boundary layer is described. The model has three coupled components: a microphysics module that resolves the size distributions of aerosols and cloud droplets. a turbulence module that treats vertical mixing between layers, and a multiple wavelength radiative transfer module that calculates radiative heating rates and cloud optical properties.

The results of a 12-h model simulation reproduce reasonably well the bulk thermodynamics, microphysical properties, and radiative fluxes measured in an $\sim 500-\mathrm{m}$ thick, summertime marine stratocumulus cloud layer by Nicholls. However, in this case, the model predictions of turbulent fluxes between the cloud and subcloud layers exceed the measurements. Results of model simulations are also compared to measurements of a marine stratus layer made under gale conditions and with measurements of a high, thin marine stratocumulus layer. The variations in cloud properties are generally reproduced by the model, although it underpredicts the entrainment of overlying air at cloud top under gale conditions.

Sensitivities of the model results are explored. The vertical profile of cloud droplet concentration is sensitive to the lower size cutoff of the droplet size distribution due to the presence of unactivated haze particles in the lower region of the modeled cloud. Increases in total droplet concentrations do not always produce less drizzle and more cloud water in the model. The radius of the mean droplet volume does not correlate consistently with drizzle, but the effective droplet radius does. The greatest impacts on cloud properties predicted by the model are produced by halving the width of the size distribution of input condensation nuclei and by omitting the effect of cloud-top radiative cooling on the condensational growth of cloud droplets. The omission of infrared scattering produces noticeable changes in cloud properties. The collection efficiencies for droplets $<30-\mu \mathrm{m}$ radius, and the value of the accommodation coefficient for condensational droplet growth, have noticeable effects on cloud properties. The divergence of the horizontal wind also has a significant effect on a 12-h model simulation of cloud structure.

Conclusions drawn from the model are tentative because of the limitations of the ID model framework. A principal simplification is that the model assumes horizontal homogeneity, and, therefore, does not resolve updrafts and downdrafts. Likely consequences of this simplitication include overprediction of the growth of droplets by condensation in the upper region of the cloud, underprediction of droplet condensational growth in the lower region of the cloud, and underprediction of peak supersaturations.
\end{abstract}

\section{Introduction}

Low-lying marine stratiform clouds cover a third of the ocean surface and play an important role in the earth's radiative heat balance (Warren et al. 1988). Because cloud-top temperatures are similar to surface temperatures, the longwave radiative impact of these clouds on the global heat budget is minor; however, because they reflect much more sunlight than the underlying ocean surface, they strongly affect the global albedo. It has been estimated that the global cooling that would result from a $4 \%$ increase in areal coverage by marine stratocumulus clouds would offset the ex-

Corresponding author address: Dr. Peter V. Hobbs, Department of Atmospheric Sciences. AK-40. University of Washington, Seattle, WA 98195 pected warming from a doubling of atmospheric carbon dioxide (Randall et al. 1984). Twomey et al. (1984) demonstrated that the reflectivity of water clouds with modest optical depths increases as the abundance of cloud condensation nuclei ( $\mathrm{CCN}$ ) increases. Albrecht (1989) argued that the fractional coverage of marine stratocumulus clouds is regulated by the drizzle rate, which regulates and is regulated by $\mathrm{CCN}$ abundance. Ackerman et al. (1993) showed through model simulations that marine stratocumulus cloud layers may limit their own lifetimes by depleting $\mathrm{CCN}$; this is because vertical mixing in the stratocumulus-topped marine boundary layer depends on cloud optical depth. which is itself dependent on droplet concentrations and therefore $\mathrm{CCN}$. Evidence that increases in $\mathrm{CCN}$ concentrations can increase cloud albedo and decrease drizzle is provided by linear high-albedo cloud features seen in marine stratiform clouds; these features, which 
are often hundreds of kilometers long, are known as "ship tracks" because they are caused by ships (Conover 1966; Coakley et al. 1987; Radke et al. 1989; King et al. 1993). These results and observations indicate that cloud microphysics plays an important role in determining the global albedo of marine stratiform clouds.

Models of the stratocumulus-topped marine boundary layer range in complexity from a single mixed layer scheme (Lilly 1968) to 3D large-eddy simulations (Deardorff 1980; Moeng 1986). Between these extremes are multilevel ensemble-averaged turbulence models, in which the combined effects of all eddy sizes are parameterized. Turbulence closure for models in the latter category include higher-ordered closure schemes in ID (e.g., Chen and Cotton 1987; Bougeault 1985 ) and in 2D (e.g., Moeng and Arakawa 1980). The $E-\epsilon$ closure method of Duynkerke and Driedonks ( 1987 ) predicts gradient transfer coefficients for turbulent fluxes through the turbulent kinetic energy $(E)$ and its viscous dissipation rate $(\epsilon)$. Although Holtslag and Moeng ( 1991 ) have described how to parameterize countergradient diffusion in convective boundary layers, the present model simply treats turbulent transport through the assumption of downgradient diffusion.

In most models of marine stratocumulus, thermodynamics and cloud microphysics are reduced to the solution of conservation equations for entropy and total water, which are partitioned into their components by bulk condensation schemes. Chen and Cotton (1987) parameterized the production of drizzle (which they found to play a significant role in the turbulent structure of the boundary layer). Nicholls (1987) investigated the production of drizzle through explicit cloud microphysics modeling, but his turbulence model was prescribed rather than predictive, and the nucleation of cloud droplets was not treated.

In this paper we present a model developed for investigating the effects of cloud microphysics on the dynamics and structure of the stratocumulus-topped marine boundary layer. We have coupled an $E-\epsilon$ turbulence mixing model with a size-resolved aerosol and cloud microphysics model (Toon et al. 1988) and a sophisticated radiative transfer code (Toon et al. 1989 a). Our study focuses on cloud microphysics and optical properties, at the expense of a highly simplified treatment of air motions. One motivation for developing such a model is to see how well it can reproduce the real atmosphere, despite the inherent simplifications. Another reason for developing a model with simplified treatment of air motions is to investigate aerosolcloud interactions that evolve over timescales that are prohibitively long to investigate with more sophisticated models and current computational constraints.

Following a description of the model its outputs are compared to observations from the North Sea described by Nicholls (1984) and Nicholls and Leighton (1986).
We then discuss some of the assumptions and sensitivities of the model.

\section{Model description}

To represent the stratocumulus-topped marine boundary layer, we have developed a $1 \mathrm{D}$, horizontally homogeneous, Eulerian model that has three coupled components: aerosol and cloud microphysics, turbulent mixing, and radiative transfer. These components and some numerical computational issues are described in this section.

\section{a. Aerosol and cloud microphysics}

The cloud microphysics model treats two types of particles: condensation nuclei ( $\mathrm{CN}$ ) and water droplets. The $C N$ are haze particles in stable equilibrium with the humidity in each layer of the model. The particle size distributions are represented by $C(r, z, t)$, where $C d r$ is the mean number concentration of particles with radii between $r$ and $r+d r$ at height $z$ and time $t$. The analytic form of the particle continuity equation that the model solves for each particle size and type is

$$
\begin{aligned}
& \frac{\partial C}{\partial t}-\frac{C}{\rho} \frac{\partial(\rho w)}{\partial z}+\frac{\partial}{\partial z}\left[\left(w-v_{\mathrm{f}}\right) C\right] \\
& -\frac{\partial}{\partial z}\left[\frac{K_{\mathrm{m}}}{\sigma_{\mathrm{p}}} \rho \frac{\partial(C / \rho)}{\partial z}\right]=S_{\mathrm{n}}-R_{\mathrm{n}} C+\frac{\partial\left(g_{\mathrm{r}} C\right)}{\partial r} \\
& +\int_{r_{\min }}^{r} \mathbf{K}_{\mathrm{c}}\left(r, r^{3}-r^{\prime 3}\right) C\left(r^{\prime}\right) C\left(r^{3}-r^{\prime 3}\right) d r^{\prime} \\
& -C \int_{r_{\min }}^{r_{\max }} K_{\mathrm{c}}\left(r, r^{\prime}\right) C\left(r^{\prime}\right) d r^{\prime}
\end{aligned}
$$

In this equation, $\rho(z, t)$ is the mean density of dry air, $w(z)$ the prescribed mean vertical air velocity, $v_{\mathrm{f}}(r, z)$ a particle fall velocity, $K(z, t)$ a gradient-transfer coefficient, $\sigma_{\mathrm{p}}$ a turbulent Prandtl number (the ratio of the eddy diffusivities for momentum and particles $), S_{n}(r$, $z, t)$ a source term of particles, $R_{11}(r, z, t)$ a particle removal rate, $g_{\mathrm{r}}(r, z, t)$ a condensational growth rate, and $K_{\mathrm{c}}\left(r, r^{\prime}, z, t\right)$ a coalescence kernel (symbols are listed in appendix $A)$. The second term on the left side of Eq. (1) represents the horizontal divergence that compensates for any change in air density due to vertical convergence. The third term on the left side of (1) represents the divergence of the vertical flux due to advection and sedimentation, and the fourth term is for the divergence of the vertical flux due to turbulent diffusion.

On the right side of $(1)$, the source term accounts for the creation of entirely new $\mathrm{CN}$, while conversions between $\mathrm{CN}$ and droplets appear as source and removal terms. The third term on the right side of $(1)$ represents the flux divergence in radius space due to condensational growth and evaporation of water. The first inte- 
gral represents the creation of particles of radius $r$ due to collisions between smaller particles, and the second integral represents the loss of particles of radius $r$ due to collisions with other particles. The collision integrals are summed over the particle classes as described by Toon et al. (1988).

The particle size distributions for $\mathrm{CN}$ and droplets are each divided into 50 bins with geometrically increasing size, such that the particle volume doubles between successive bins, resulting in a radius grid that spans from $r_{\min }=0.005 \mu \mathrm{m}$ to $r_{\max }=500 \mu \mathrm{m}$. Within each droplet size bin, the model solves a continuity equation for the total volume concentration of dissolved cloud condensation nuclei ( $C C N$ ) to allow calculation of the equilibrium reduction in droplet vapor pressure (the solute effect). Keeping track of the volume of dissolved $\mathrm{CCN}$ allows the model to conserve solute mass. Because particles are circulated in the marine boundary layer between unactivated haze particles below cloud base and cloud droplets within the cloud, the evaporation of droplets to haze particles must be treated carefully. The total volume of dissolved $\mathrm{CCN}$ within a droplet size bin is not enough information to adequately treat the evaporation of droplets from a varying distribution of $\mathrm{CCN}$ sizes. Following the ideas of Turco et al. (1979), our model carries the second moment of the CCN volume distribution within each droplet size bin, from which the width of the dissolved $\mathrm{CCN}$ distribution is calculated. The coagulation expressions for CCN volume and volume-squared differ from those for droplet number. This difference occurs because collisions between particles cause the number of droplets to decrease, while the total particle volume remains unchanged, and the total volume-squared increases.

The model calculates the concentration of water vapor by treating vapor exchange with droplets, and vertical transport by turbulent diffusion and advection. Defining $G(z, t)$ as the mean mass concentration ( units of $\mathrm{g} \mathrm{cm}^{-3}$ ) of water vapor at height $z$ and time $t$, the analytic form of the vapor continuity equation that the model solves is

$$
\begin{aligned}
\frac{\partial G}{\partial t}- & \frac{G}{\rho} \frac{\partial(\rho w)}{\partial z}+\frac{\partial}{\partial z}(w G)-\frac{\partial}{\partial z}\left[\frac{K_{\mathrm{m}}}{\sigma_{\mathrm{h}}} \rho \frac{\partial(G / \rho)}{\partial z}\right] \\
& =-\frac{4 \pi}{3} \rho_{\mathrm{w}} \int_{r_{\min }}^{r_{\max }} r^{\prime 3} \frac{d}{d r^{\prime}}\left[g_{\mathrm{r}}\left(r^{\prime}\right) C\left(r^{\prime}\right)\right] d r^{\prime}
\end{aligned}
$$

where $\rho_{w}$ is the density of liquid water, and $\sigma_{h}$ the turbulent Prandtl number for heat (assumed to be the same as that for vapor; Stull 1988). The right side of Eq. (2) represents vapor exchange with droplets (water in haze particles is ignored for all but the radiative calculations). Below we describe the analytic forms of the terms appearing in these equations and the boundary conditions.

\section{1) CONDENSATIONAL GROWTH}

Droplet condensational growth is treated within each model layer using an average value of the supersaturation (calculated from the predicted values of water vapor concentration and temperature), in which the calculation averages over updrafts and downdrafts. Because of this averaging process, the model does not represent the horizontal variability of real clouds, in which supersaturations are expected to be higher in updrafts than in downdrafts. The growth equation that we use treats the effects on droplet temperature of radiative transfer. We use a form similar to that employed by Barkstrom (1978):

$$
\begin{gathered}
g_{\mathrm{r}} \equiv \frac{d r}{d t}=\frac{g_{0} n_{\mathrm{vap}}\left(S+1-A_{\mathrm{k}} A_{\mathrm{s}}+g_{1} g_{2} q_{\mathrm{rad}}\right)}{1+g_{0} g_{1} n_{\text {vap }}} \\
g_{0}=\frac{D F_{1} M_{\mathrm{w}}}{A_{v} \rho_{\mathrm{w}} r} \quad g_{1}=\frac{L_{\nu}, M_{\mathrm{w}} \rho_{\mathrm{w}} r}{R T^{2} K_{\mathrm{r}} F_{\mathrm{r}}} \quad g_{2}=\frac{1}{L_{1}, r^{2} \rho_{\mathrm{w}}},
\end{gathered}
$$

in which $n_{\text {vap }}$ is the saturation vapor pressure (expressed as a number density, with units of molecules $\left.\mathrm{cm}^{-3}\right)$, and $S$ the supersaturation of water vapor ( $S=\left\lfloor n_{s} / n_{\text {vap }}\right\rfloor-1$, where $n_{\infty}$ is the ambient vapor pressure: $n_{\gamma}=G A_{v} / M_{w}$ ). The gas kinetic corrections to the diffusion coefficient of water vapor, $D$, and the thermal conductivity, $K_{t}$, are described by Toon et al. $(1989 \mathrm{~b})$. In these expressions the condensation coefficient (called the mass accommodation coefficient by Toon et al.) and the thermal accommodation coefficients are taken to be unity. The factors $F_{\mathrm{v}}$ and $F_{1}$ are ventilation corrections, which account for the effects of droplet sedimentation on the flux of water vapor molecules and heat $t o$ and from the droplets; we use the functions recommended by Pruppacher and Klett (1978). The factors $A_{\mathrm{k}}$ and $A_{\mathrm{s}}$ in (3) account for, respectively, the increase in vapor pressure exerted by the droplet due to curvature (the Kelvin effect) and its reduction due to the solute effect. They are given by

$$
A_{\mathrm{k}}=\exp \left(\frac{2 M_{\mathrm{w}} \sigma_{\mathrm{w}}}{r \rho_{\mathrm{w}} R T}\right) A_{\mathrm{s}}=\exp \left(-\frac{\nu_{\mathrm{d}} \Phi_{\mathrm{s}} m_{\mathrm{s}} M_{\mathrm{w}}}{m_{\mathrm{w}} M_{\mathrm{s}}}\right)
$$

The solute composition determines the values of the remaining factors in $A_{k} ; \nu_{\mathrm{u}}$ is the dissociativity of the dissolved CCN (for ammonium bisulfate, $\nu_{\mathrm{d}}=2$ ), $\Phi$, the practical osmotic coefficient (we use a value of 1 , which is valid for dilute solutions ), and $m_{\mathrm{s}}$ the mass of dissolved CCN, which is equal to the density of the solute times the average CCN volume in a droplet size bin.

The $q_{\text {rad }}$ term in Eq. (3) accounts for the radiative heating rate of droplets:

$$
q_{\mathrm{rad}}=\int_{\nu_{\operatorname{man}}}^{\nu_{\max }} k_{\mathrm{abs}}(J-B) d \nu,
$$

where $J(\nu)$ and $B(\nu)$ are, respectively, the mean radiative intensity and the Planck function in a model 
layer, $k_{\mathrm{ahs}}(\nu, r)$ the absorption coefficient for a droplet (from Mie calculations, described below), and the integration is over frequency, $\nu$.

Treatment of the rapid time rate of change in the sizes of haze droplets would require exceedingly small time steps (small fractions of a second), because their growth rates are so large in relation to their sizes. To allow the model to take longer time steps (typically on the order of seconds), the growth of haze droplets in subsaturated air is not treated explicitly. Thus, the Kelvin and solute factors are ignored when evaluating the growth rate for haze droplets (for which $A_{\mathrm{k}} A_{\mathrm{s}}<$ 1). By ignoring $A_{\mathrm{k}} A_{s}$, all haze droplets evaporate when the relative humidity is $<100 \%$; ultimately they are transformed from droplets to $\mathrm{CN}$, as described below.

\section{2) CCN ACTIVATION}

The $\mathrm{CN}$ in a size bin are activated to $\mathrm{CCN}$ when $S$ exceeds $S_{\text {cril }}$, where the value of the critical supersaturation ( $S_{\text {crit }}$ ) corresponds to the mass of one CN particle. In the absence of the radiative term $q_{\text {rad }}$, the maximum value of $S$ for which a droplet can maintain stable equilibrium with respect to condensation ( $S_{\text {cri. K }}$ ) can be calculated from a simplified form of the Köhler equilibrium relations (Pruppacher and Klett 1978 ). The corresponding droplet radius is $r_{\text {crit }}$. Because we include the radiative term $q_{\text {rad }}$ in the droplet condensation equation, we also take it into account in the determination of $S_{\text {crit }}$. This is done by evaluating $S_{\text {cri }}=S_{\text {crit,K }}+g_{1} g_{2} q_{\text {rad }}$, where the terms on the right side are evaluated at $r_{\mathrm{cr}}$. A more rigorous treatment would be to determine a new $r_{\text {crit }}$ that also takes into account $q_{\text {rad }}$, but for the conditions and droplet sizes that we consider we have found this refinement to be unnecessary. Including $q_{\text {rad }}$ reduces the magnitude of $S_{\text {crit }}$ in regions of radiative cooling. Although $S_{\text {crit }}$ can be $<0$, we do not allow CCN activation under subsaturated conditions.

Activation appears as a nearly instantaneous removal rate $\left(10^{3} \mathrm{~s}^{-1}\right)$ in the $\mathrm{CN}$ equations, and it appears as a corresponding source term in the droplet and dissolved $\mathrm{CCN}$ equations. When a nucleated particle first appears in a droplet size bin it contains no water; however, the resulting large solute effect causes it to grow rapidly through its $r_{\text {crit }}$ value.

\section{3) TOTAL EVAPORATION OF DROPLETS}

Condensation nuclei are created when the evaporation of a droplet to the next smallest size bin would remove all of the water. This occurs when the average volume of dissolved CCN in a droplet exceeds the droplet volume, or when the average volume-squared of dissolved CCN exceeds the square of the droplet volume. When evaporation from a droplet bin would produce either of these conditions, the number of drop- lets and the volume of CCN still undergo condensational loss, but instead of being a source to the next smaller droplet size bin, they are a source of $\mathrm{CN}$. The dissolved $\mathrm{CCN}$ is distributed over the $\mathrm{CN}$ size distribution in a similar manner to that described by Turco et al. (1979). The method fits the dissolved CCN volume to a lognormal probability distribution function, and distributes the $C \mathrm{CN}$ volume over the $\mathrm{CN}$ grid in a manner that conserves both volume and number. Since it would be unrealistic to allow accumulation of $\mathrm{CN}$ that are too small to have ever been activated, particles are only evaporated into $\mathrm{CN}$ bins of sizes larger than the smallest $\mathrm{CN}$ that has been activated to a droplet over the entire model domain in the previous hour of simulation.

\section{4) Particle collisions}

Collisions include the thermal coagulation of particles due to their Brownian motion and the gravitational collection of particles due to differences in their fall speeds. In Eq. ( 1$), K_{\mathrm{c}}$ is the sum of the thermal coagulation kernel $\left(K_{\mathrm{B}}\right)$ and the gravitational collection kernel $\left(K_{\mathrm{g}}\right)$. Our treatment of thermal coagulation uses the kernel given by Fuchs ( 1964 ) for spheres. Turbulence and phoretic forces are ignored. For gravitational collection we use the standard definition for the geometric collection efficiency between particles of radius $r$ and $r^{\prime}$ :

$$
K_{\mathrm{g}}\left(r, r^{\prime}\right)=\pi\left(r+r^{\prime}\right)^{2} E\left(r, r^{\prime}\right)\left|v_{\mathrm{f}}(r)-v_{\mathrm{f}}\left(r^{\prime}\right)\right|,
$$

where $E\left(r, r^{\prime}\right)$ is the geometric collection efficiency between the particles (equal to the product of the collision and coalescence efficiencies), and $v_{\mathrm{f}}$ a particle fall speed. The collision efficiencies are interpolated from the values used by Hall (1980), which derive from a number of sources. For coalescence efficiencies we have used the formulation of Beard and Ochs (1984).

\section{5) Transport}

Particles are transported by three processes: sedimentation, turbulent diffusion, and advection. The expressions used for sedimentation velocities apply to two regimes. For Reynolds numbers $<10^{-2}$ ( $r$ $\leqslant 10 \mu \mathrm{m})$ we employ a Stokes-Cunningham expression (Toon et al. 1989b). For larger Reynolds numbers there are no analytic expressions for the fall speeds; we use the interpolation developed by Beard (1976). For turbulent diffusion we set the turbulent Prandtl numbers for particles and heat to unity. Gradient transfer coefficients are taken from the turbulence model; their evaluation is described in the section on turbulent mixing.

Advection is specified through a fixed profile of vertical wind $(w)$, which is calculated from the prescribed 
divergence rate of the horizontal wind (div). Assuming that the divergence rate is independent of height, the vertical wind profile is

$$
w=\frac{\operatorname{div}\left(p_{\mathrm{surf}}-p\right)}{g \rho_{r=0}}
$$

[Equation ( 7 ) simplifies to $w \approx \operatorname{div} \cdot z$ in the boundary layer]. Because we represent continuity equations in flux form, the air continuity equation appears implicitly. Under conditions of vertical velocity convergence, air will accumulate if unbalanced by horizontal divergence, thereby altering the predicted state variables (in which $\rho$ is implicit). To avoid an increase of air density, the vertical flux convergence of air is balanced by a horizontal divergence term / the second term on the left side of Eq. (1) ]. In a sensitivity test presented below, air is allowed to accumulate (as it does when surface pressure builds ) by omitting this horizontal divergence term.

\section{6) NEW PARTICLE CREATION}

New sulfate particles are introduced to the model domain by specifying a production rate at each grid point, which is described by a lognormal size distribution of $\mathrm{CN}$. Because the growth of embryonic $\mathrm{CN}$ due to gas-to-particle conversion is not treated, these particles are introduced at accumulation mode sizes ( $r$ $\sim 0.1 \mu \mathrm{m})$. The parameters that must be specified are the particle production rate, and the geometric mean number radius $\left(r_{n}\right)$ and standard deviation $(\sigma)$ of the $\mathrm{CN}$ distribution. The values chosen are described below.

\section{7) BOUNDARY CONDITIONS}

The flux of particles across the lower boundary of the model is given by

$$
F_{\mathrm{C}}=-C\left(z_{1}\right)\left[\nu_{\text {dep.p }}+\nu_{1}\right] \text {, }
$$

where $z_{1}$ is the altitude of the midpoint of the layer. The only deposition velocity $\left(\nu_{\text {dep.p }}\right)$ that we consider in Eq. (8) is that due to gravity; phoretic forces are ignored. The deposition velocity is given by Giorgi (1986), which treats transfer across the dynamic sublayer where turbulent motions drive mixing, as well as transfer across the viscous layer where mixing is due to molecular motion. The deposition velocities depend upon the atmospheric stability and wind speed near the surface, and are linked to the surface boundary conditions of the turbulence model (described below).

The flux of water vapor across the lower boundary of the model is given by

$$
F_{\mathrm{G}}=-v_{\text {dep.v }}\left[G\left(z_{1}\right)-G\left(z_{s}\right)\right] \text {. }
$$

In this expression, $v_{\mathrm{dep}, \mathrm{v}}$ is the deposition velocity for water vapor molecules, which we also evaluate using
Giorgi's ( 1986 ) parameterization. Giorgi's parameterization involves several nondimensional numbers: for water vapor molecules both the drift velocity and the Stokes number are zero, the Schmidt number is the ratio between the diffusivities of water vapor and air, and the heat transfer coefticient (described in appendix $C$ ) is used in place of the drag coefficient. Here $G\left(z_{1}\right)$ is the concentration of water vapor in the lowest layer, and the concentration of water vapor at the surface, $G\left(z_{\mathrm{s}}\right)$, corresponds to $98.3 \%$ relative humidity at the temperature of the sea surface, in accordance with Raoult's law.

When the divergence rate is zero, particles and water vapor have no fluxes at the top of the model; otherwise the fluxes into the top of the model are set equal to the advective fluxes out of the bottom of the highest grid layer, so that the concentrations in the top layer are not changed by advection.

\section{b. Turbulent mixing}

\section{1) Governing equations}

We use a gradient transfer approach to model turbulent fluxes. The evolution equations for the dynamics and thermodynamics of the cloud-topped boundary layer are expressed in flux form:

$$
\begin{aligned}
& \frac{\partial(\rho u)}{\partial t}-u \frac{\partial(\rho w)}{\partial z}+\frac{\partial(w \rho u)}{\partial z}-\frac{\partial}{\partial z}\left(K_{\mathrm{m} \rho} \rho \frac{\partial u}{\partial z}\right) \\
& =\rho f\left(v-v_{g}\right) \\
& \frac{\partial(\rho v)}{\partial t}-v \frac{\partial(\rho w)}{\partial z}+\frac{\partial(w \rho v)}{\partial z}-\frac{\partial}{\partial z}\left(K_{\mathrm{m}} \rho \frac{\partial v}{\partial z}\right) \\
& =\rho f\left(u_{\mathrm{y}}-u\right) \\
& \frac{\partial(\rho \theta)}{\partial t}-\theta \frac{\partial(\rho w)}{\partial z}+\frac{\partial(\rho w \theta)}{\partial z}-\frac{\partial}{\partial z}\left(\frac{K_{\mathrm{m}}}{\sigma_{\mathrm{h}}} \rho \frac{\partial \theta}{\partial z}\right) \\
& =\frac{\theta}{c_{\mathrm{p}} T_{0}}\left[\frac{\partial F_{\mathrm{net}}}{\partial z}-L_{\mathrm{v}}\left(\frac{\partial G}{\partial t}\right)_{\text {phase }}\right] \text {. }
\end{aligned}
$$

The components of the geostrophic wind, $u_{\mathrm{g}}$ and $\nu_{\mathrm{g}}$, are fixed, and independent of altitude. Thermodynamics is influenced by radiative transfer through the divergence of the net upward radiative flux. The effect of cloud microphysics appears through the phase change of $G$, the water vapor concentration.

The essence of the $E-\epsilon$ closure method is to diagnose the values of $K_{\mathrm{n}}$ from the predicted values of the turbulent kinetic energy $E$ and its viscous dissipation rate $\epsilon$, through the relation $K_{\mathrm{m}}=c_{\mu} E^{2} / \epsilon$. The values of $c_{\mu}$ and all the constants used in the turbulence model are taken from Duynkerke (1988).

The turbulent kinetic energy equation used in the model is 


$$
\begin{aligned}
& \frac{\partial(\rho E)}{\partial t}=\underbrace{E \frac{\partial(\rho w)}{\partial z}-\frac{\partial(w \rho E)}{\partial z}+\frac{\partial}{\partial z}\left(\frac{K_{\mathrm{m}}}{\sigma_{\varepsilon}} \rho \frac{\partial E}{\partial z}\right)}_{\text {TRANS }} \\
& +\underbrace{K_{\mathrm{m}} \rho\left[\left(\frac{\partial \boldsymbol{u}}{\partial z}\right)^{2}+\left(\frac{\partial \hbar}{\partial z}\right)^{2}\right]}_{\text {SHEAR }}+\underbrace{\frac{\rho g}{\theta_{\mathrm{v} z}} \overline{w^{\prime} \theta_{v}^{\prime}}}_{\text {BUOY }}-\rho \epsilon . \quad(11)
\end{aligned}
$$

The sources of $E$ are transport (TRANS), shear (SHEAR), and buoyancy (BUOY). The pressure-velocity covariance is implicit in the gradient transport component of TRANS (Duynkerke and Driedonks 1987 ). The buoyancy flux is computed from the turbulent flux of virtual potential temperature, which is defined by $\theta_{v}=\theta\left(1+0.61 q_{v}-q_{1}\right)$, where $q_{v}$ is specific humidity and $q_{1}$ the specific liquid water content. For the temperate conditions we are considering, $q_{v}$ and $q_{1}$ are indistinguishable from the vapor and liquid water mass mixing ratios, respectively:

$$
q_{v}=\frac{G}{\rho+G} \approx \frac{G}{\rho} \text { and } q_{1}=\frac{\rho_{1}}{\rho_{1}+\rho} \approx \frac{\rho_{1}}{\rho},
$$

where the concentration of liquid water in a layer is calculated by integrating the volume of water in the droplet size distribution. Because $\theta_{v}$ is not conserved under saturated conditions, gradient transport of $\theta_{v}$ is used only for unsaturated air. For saturated air it is assumed that perturbations in vapor correlate with perturbations in temperature according to the Clausius-Clapeyron relation, and an expression for BUOY can be derived from the gradient transfer of two semi-conservative variables: equivalent potential temperature $\left(\theta_{\mathrm{e}}\right)$ and specific total water content $\left(q_{1}\right)$. Duynkerke and Driedonks (1987) and Duynkerke (1988) used an "all or nothing" condensation scheme for their buoyancy flux treatment; we use a partial condensation scheme as described by Bougeault (1981). In the partial condensation scheme, the saturated and unsaturated fluxes are combined through a weighting factor that represents the fraction of saturated air at a given level. Our model assumes an exponential probability distribution of the total water and liquid potential temperature $\left(\theta_{1}\right)$, the covariance of which is taken from Mellor and Yamada (1982). Details for the evaluation of BUOY are given in appendix $B$. The partial condensation scheme can be used to diagnose the cloud liquid water in each model layer. However, because our model explicitly predicts cloud droplet size distributions, this diagnosed cloud liquid water is not used.

The most difficult quantity to model is $\epsilon$. We use the flux form of the $\epsilon$ equation given by Duynkerke (1988):

$$
\begin{aligned}
& \frac{\partial(\rho \epsilon)}{\partial t}-\epsilon \frac{\partial(\rho w)}{\partial z}+\frac{\partial(w \rho \epsilon)}{\partial z}-\frac{\partial}{\partial z}\left(\frac{K_{\mathrm{m}}}{\sigma_{t}} \rho \frac{\partial \epsilon}{\partial z}\right) \\
& =\frac{\epsilon}{E}\left(c_{1,} P-c_{2 \epsilon} \rho \epsilon\right) \text {, }
\end{aligned}
$$

in which $c_{1}$, and $c_{2}$, are constants, and $P$ is the local production of $E$ :

$$
P=\operatorname{SHEAR}+\max (0, \text { BUOY })+\max (0, \text { TRANS }) .
$$

The inclusion of the transport term in $P$ was determined by Duynkerke (1988) to be a necessary extension to the standard $E-\epsilon$ model, enabling the model to produce results from the neutral boundary layer in agreement with higher-order closure models.

All of the governing equations are solved using the same numerical methods applied to the cloud microphysics continuity equations described by Toon et al. (1988), where the tracer concentration analogs in $z \mathrm{co-}$ ordinates are $\rho u, \rho \nu, \rho \theta, \rho E$, and $\rho \epsilon$. Because $E$ and $\epsilon$ are evaluated at grid layer boundaries, their transport requires gradient transfer coefficients to be interpolated from their values at layer boundaries, for which we use linear interpolation. We also use linear interpolation between grid centers for other quantities needed for the evaluation of buoyancy fluxes at layer boundaries. $\mathrm{Be}$ cause of the nonlinear dependence of saturation vapor pressure on temperature, we evaluate vapor pressure at the layer boundaries using the interpolated temperatures.

\section{2) BOUNDARY CONDITIONS}

Surface momentum fluxes are evaluated through bulk transfer coefficients:

$$
F_{p u}=-c_{\mathrm{d}} \operatorname{M\rho u}\left(z_{1}\right) \text { and } F_{p !}=-c_{\mathrm{d}} \operatorname{M} \rho v\left(z_{1}\right),
$$

where $c_{\mathrm{d}}$ is a drag coefficient, $u\left(z_{1}\right)$ and $v\left(z_{1}\right)$ are the mean wind components, and $M=\left[u\left(z_{1}\right)^{2}+v\left(z_{1}\right)^{2}\right]^{1 / 2}$ is the mean wind speed. The evaluation of $c_{d}$, which depends on the stability of the surface layer and the surface stress, is described in appendix C. For the surface heat flux we apply Giorgi's ( 1986 ) formulation of deposition velocity to the transport of heat, analogous to our treatment of vapor:

$$
F_{\rho \theta}=-\rho v_{\text {dep }, \theta}\left[\theta\left(z_{1}\right)-\theta\left(z_{s}\right)\right],
$$

where $z_{\mathrm{s}}$ refers to the surface value and the deposition velocity is nearly the same as that for vapor (except that the Schmidt number for heat is the ratio of the viscosity to the thermal diffusivity of air).

The boundary values for $E$ and $\epsilon$ are calculated at an altitude of $1.5 \mathrm{~m}$ ( $5 \%$ of the thickness of the lowermost grid layer) from the relations given by Duynkerke (1988):

$$
\begin{aligned}
& E=\frac{u_{*}^{2}}{\sqrt{c_{\mu}}}+0.35 w_{*}^{2}, \\
& \epsilon=\frac{u_{*}^{2}}{k}\left(\frac{\phi_{m}}{z}-\frac{1}{L}\right),
\end{aligned}
$$


in which the convective velocity scale $w_{*}$ is zero under stable conditions, and under unstable conditions

$$
w_{*}=\left(\frac{g}{\theta_{\mathrm{v} 0}}\left(\bar{w}^{\prime} \bar{\theta}_{v}^{\prime}\right), z^{1 / 1}\right)^{1 / 3} .
$$

In the highest layer of the model, the values of $u, v$, and $\theta$ are all fixed at their initial values. The fluxes of $E$ and $\epsilon$ are set to zero at the top of the model.

\section{c. Radiative transfer}

\section{1) General description}

The radiative transfer model is used to calculate radiative heating rates for use in the thermodynamic equation and in the droplet condensational growth term, and to calculate cloud optical properties. Only an overview is presented here, since the details of the techniques are described by Toon et al. (1988).

The model treats multiple scattering over 26 solar wavelengths $(0.26 \mu \mathrm{m}<\lambda<4.3 \mu \mathrm{m})$, and absorption and scattering over 14 infrared wavelengths $(4.4 \mu \mathrm{m}$ $<\lambda<62 \mu \mathrm{m}$ ). Blackbody energy beyond those wavelength domains is included to agree with the StefanBoltzmann law (though neither absorption nor scattering are treated beyond the wavelength domains). An exponential sum formulation is used to treat gaseous absorption coefficients. The optical properties of particles are determined through Mie calculations, in which the complex refractive index for liquid water is used, as interpolated from the datasets of Painter et al. (1969), Palmer and Williams (1974), and Downing and Williams (1975). Mie calculations are averaged over six radius subdivisions for each particle size bin.

The distributions of particles, water vapor, and temperature are taken from the cloud microphysics and turbulent transport modules. Carbon dioxide is specified to be $340 \mathrm{ppmv}$, and the ozone profile is taken from the U.S. Standard Atmosphere (NOAA 1976). For the radiative transfer calculations, the $C N$ distribution is transformed from dry radius to the wet radius in equilibrium with the average relative humidity in each layer, which is not allowed to exceed $99.9 \%$ for this calculation.

\section{2) BOUNDARY CONDITIONS}

The grid for radiative transfer includes one layer that lies above the grid used in the other modules. This layer (indicated by 0 ) is specified to be devoid of particles, its temperature is taken to be the same as that in the underlying layer, and the column of water vapor in the extra layer is fixed. Because the isothermal profile is an unrealistic representation of the actual atmospheric structure, we impose a downwelling source of longwave radiation into the top of layer 0 . The solar zenith angle as a function of time is calculated using standard methods. The reflectivity of the surface is fixed at $7 \%$ for all solar wavelengths and incident angles; its emissivity is taken to be unity.

\section{d. Numerical issues'}

For the sake of clarity we have presented the continuity equations above using geometric altitude $(z)$ as the vertical coordinate; operationally, however, the equations are cast and solved using nondimensional pressure (sigma) as the vertical coordinate. The numerical algorithms used by the model to solve the continuity equations are described by Toon et al. (1988).

Below the highest level of the radiative transfer model, the grid is divided into 50 layers. The layer nearest the surface is $30 \mathrm{~m}$ thick. Layer thickness decreases upward $1010-\mathrm{m}$ resolution at the initial altitude of the inversion, above which the thickness is constant (at $10 \mathrm{~m}$ ). The increased resolution above the initial height of the inversion allows the boundary layer to deepen unimpeded by resistance that can be caused by decreasing the vertical resolution upward of the inversion. Using thinner layers did not affect the model results. The variables on the grid are staggered as follows: the concentrations of particles and vapor, as well as horizontal winds and temperature, are defined at layer midpoints; vertical wind, gradient transfer coefficients, turbulent kinetic energy and its dissipation rate, and radiative fluxes are defined at layer boundaries.

To avoid numerical instabilities, a variable time step is used. At each time step, the concentration of droplets in bins within $1 \%$ of the peak concentration on the grid is not allowed to change by more than a factor of two. Likewise, $S$ is not allowed to change by more than a factor of two when its absolute value exceeds $10^{4}$. Finally, $E$ is not allowed to change by more than a factor of two when greater than $E_{\min }=10^{10} \mathrm{~m}^{2} \mathrm{~s}^{2}$ ( $E$ is not allowed to decrease below $E_{\text {min }}$ ). If variations exceed these limits, then all dynamic variables are reset to their values at the end of the previous time step, the length of the time step is reduced, and the calculation is repeated. In this manner the time step is allowed to vary between $5 \times 10^{-3}$ and $40 \mathrm{~s}$.

The exponential scheme used for advection on the spatial grid, described by Toon et al. (1988), is not used here because instabilities resulted from the advection due to subsidence of sharp gradients at the inversion (where mixing is negligible). Instead, upwind advection, which is numerically diffusive, is used. Because the details of the entrainment of overlying air may be important to the long-term evolution of the stratocumulus-topped marine boundary layer, the diffusive advection scheme may affect model results over long simulations.

\section{Comparisons of model results with measurements}

To investigate the extent to which the model can reproduce observations, we used two sources of data. 
The first of these is a detailed set of airborne measurements taken in a layer of stratocumulus cloud over the North Sea by Nicholls ( 1984 ) (hereafter referred to as $\mathrm{N} 84$ ). These measurements include vertical profiles of cloud microstructure, bulk thermodynamics, radiative fluxes, and turbulence through the depth of the cloudtopped boundary layer. The second source of data, which is less detailed than that of N84, consists of two sets of airborne measurements taken in stratiform clouds over the North Sea by Nicholls and Leighton (1986) (hereafter referred to as NL).

\section{a. Comparisons with the measurements of Nicholls (1984)}

\section{1) MITHOD}

The airborne measurements described by N84 (also by NL as flight 526) were obtained on 22 July 1982. Because these measurements represent a snapshot in time (averaged between 1100 and 1450 LST) of a boundary layer air mass with an uncertain history, difficulties are to be expected in reproducing them with a time-dependent model. In using this same dataset, Duynkerke and Driedonks (1987) initialized their model with the observed cloud structure and compared their model results with the measurements after 2 hours of simulation time, before the calculations departed too far from the initial state. Bougeault (1985) took another approach in comparing model results with similar observations: the model was initialized with a cloudless, stable atmosphere, simulating 7 days of evolution (when steady state was reached), and the results on noon of the fourth day were compared with the measurements. We take an intermediate approach by initializing our model with a cloudless, slightly unstable boundary layer at midnight and comparing the model results 12 hours later with the measurements of $\mathrm{N} 84$.

Since N84 did not report on particles of radius $<1$ $\mu \mathrm{m}$, we initialize the model with $1000 \mathrm{CN}$ per cubic centimeter spread uniformly through the depth of the model, with sizes specified by a lognormal distribution with $r_{\mathrm{n}}=0.05 \mu \mathrm{m}$, and $\sigma=2.5$. The $\mathrm{CN}$ composition is assumed to be ammonium bisulfate $\left(\mathrm{NH}_{4} \mathrm{HSO}_{4}\right)$, in accord with Covert's ( 1988 ) measurements of non-sea salt sulfate in the remote North Pacific. The $\mathrm{CN}$ production rate and initial concentration were chosen to attain steady droplet concentrations of the approximate number observed by N84. In Fig. 1 the CCN activation spectrum produced by this $\mathrm{CN}$ distribution is compared to those measured by Hudson and Frisbie ( 1991 ) under marine stratus over the Pacific; it can be seen that the slopes of the two spectra are generally similar. Matching the slope of an observed $\mathrm{CCN}$ activation spectra is equivalent to matching the shape of the observed $\mathrm{CN}$ size distribution (assuming the same solute composition ). At the lower supersaturations depicted in Fig. 1, the slope of the activation spectrum for our initial $\mathrm{CN}$

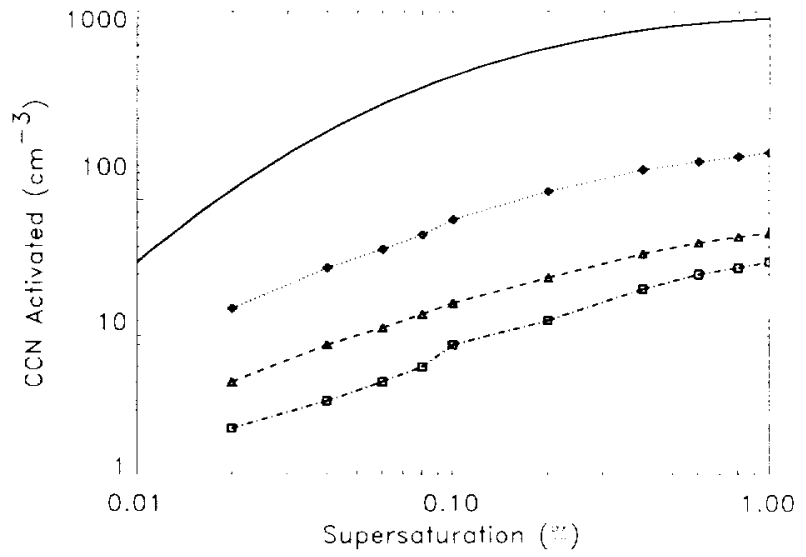

FIG. 1. Comparison of initial cumulative CCN activation spectrum used in the model calculations (solid line) with the measurements of Hudson and Frisbie (1991). The three sets of measurements were made on successive days, during which the total particle concentration was decreasing with time.

distribution is steeper than Hudson and Frisbie's measurements. The difference in slopes is consistent with adding a larger proportion of smaller particles when increasing the total particle concentration. The relatively greater increase of smaller particles at higher total particle concentrations is to be expected because the dominant source (by number) of marine aerosol is the photochemical conversion of gaseous sulfur to small sulfate particles. To maintain particle concentrations over the 12 -h simulation, $\mathrm{CN}$ are produced at a rate of $0.018 \mathrm{~cm}^{-3} \mathrm{~s}^{-1}$ in the boundary layer.

Sea surface temperatures were not reported by N84, therefore, we fix it at the climatological July value for the measurement area of $288 \mathrm{~K}$ (Tucker and Barry 1984). The temperature in the lowest layer of the model is initialized $1 \mathrm{~K}$ below the sea surface temperature, which induces a small surface buoyancy flux (initially $8 \mathrm{~W} \mathrm{~m}^{-2}$ ). The initial lapse rate follows the dry adiabat up to an inversion altitude of $800 \mathrm{~m}$, where the temperature jumps to the observed $286 \mathrm{~K}$, and is isothermal above. The relative humidity through the depth of the boundary layer is initially $98.3 \%$ ( same as the surface value), and above the inversion the water vapor mixing ratio is a constant $5 \mathrm{~g} \mathrm{~kg}^{-1}$ (the average of the observations ). The wind profile is initially geostrophic and independent of altitude, as reported by N84 $\left(u_{\mathrm{g}}=8.5 \mathrm{~m} \mathrm{~s}^{-1}, v_{\mathrm{g}}=0\right)$. No subsidence rates are reported in $\mathrm{N84}$; to limit upward entrainment of the boundary layer, we take div $=2.5 \times 10^{-6} \mathrm{~s}^{-1}$ for the simulation. This yields a subsidence rate of $0.2 \mathrm{~cm} \mathrm{~s}^{-1}$ at the initial altitude of the inversion. We fix the surface pressure at $1013 \mathrm{mb}$ (air does not accumulate in this model simulation ).

The model simulation begins at local midnight, the sun rises at 0400 local time and reaches a minimum zenith angle of $35^{\circ}$ at noon. The temperature in layer 0 

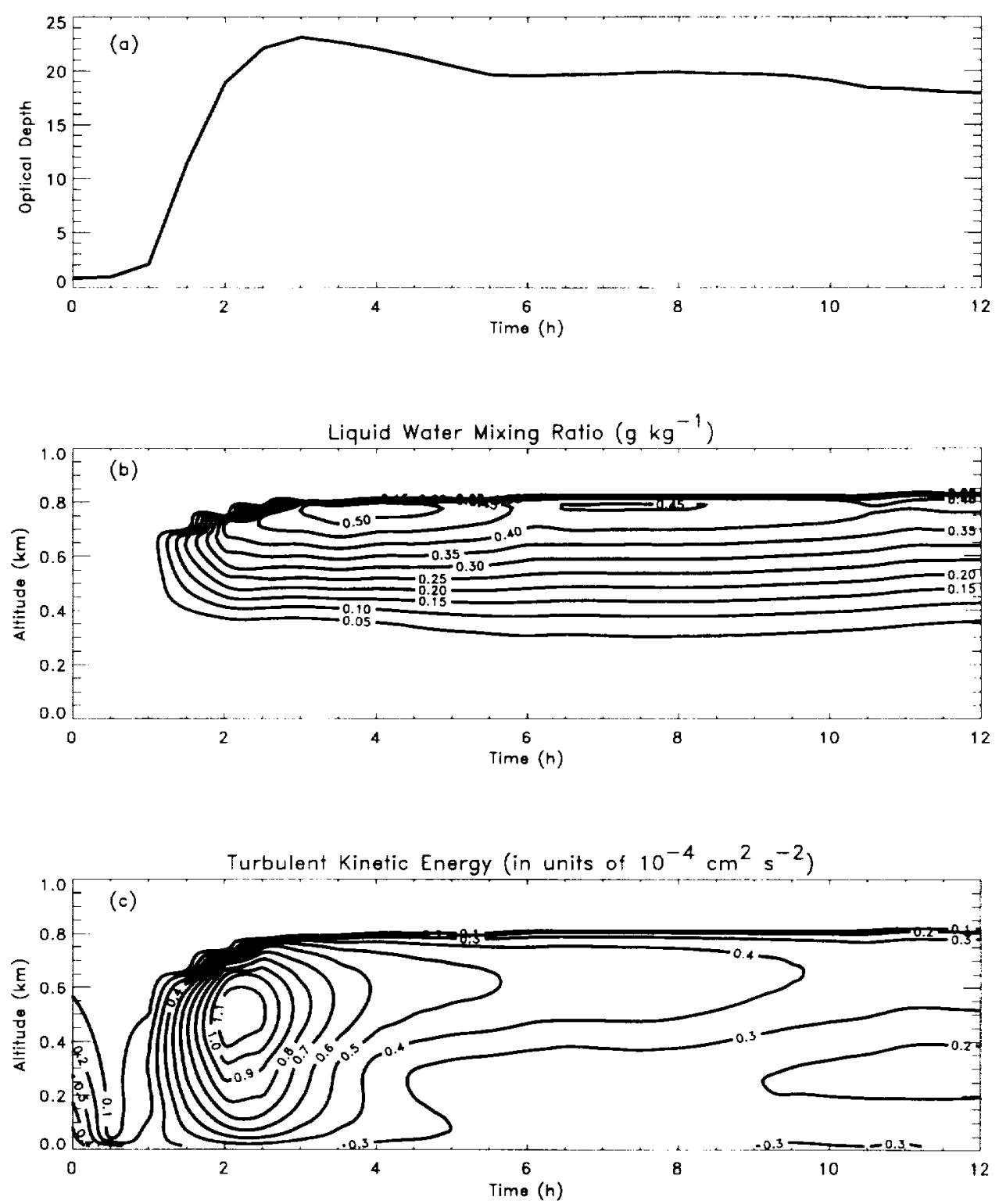

FIG. 2. Time evolution of (a) the optical depth of the modeled boundary layer (at $0.6-\mu \mathrm{m}$ wavelength), (b) the liquid water mixing ratio (in $\mathrm{g} \mathrm{kg}$ '). and (c) the turbulent kinetic encrgy (in units of $10^{4} \mathrm{~cm}^{2} \mathrm{~s}^{2}$ ). Output is made every half-hour of simulation.

(the layer in the radiative transfer scheme above the rest of the grid) is fixed at $286 \mathrm{~K}$, while the column of water vapor in layer 0 is fixed at the climatological value of $2.9 \mathrm{~g} \mathrm{~cm}^{-2}$ (midlatitude summer profile; Anderson et al. 1986). Combined with the downwelling blackbody flux at the top of the model, this structure yields a downward longwave flux of $270 \mathrm{~W} \mathrm{~m} \mathrm{~m}^{-2}$ at $900-\mathrm{m}$ altitude, in agreement with the radiative calculations of N84. While this is $15 \mathrm{~W} \mathrm{~m}^{-2}$ below the measured value, Nicholls and Leighton (1986) state that there was a systematic error in that particular measurement, and that the value calculated by $\mathrm{N} 84$ is more reliable.

\section{2) Results}

The evolution of optical depth of the modeled boundary layer provides a bulk measure of the cloud layer that develops in the model simulation (Fig. 2a). Prior to cloud formation the optical depth is dominated by extinction from the haze particles in the moist boundary layer. After $1.5 \mathrm{~h}$ of simulation, enough vapor has diffused upward to saturate the air and condense into a cloud, as seen in the time-height contour plot of $q_{1}$ (Fig. 2b). The release of latent heat "shocks" the modeled atmosphere, as a large release of buoyancy 
(a)

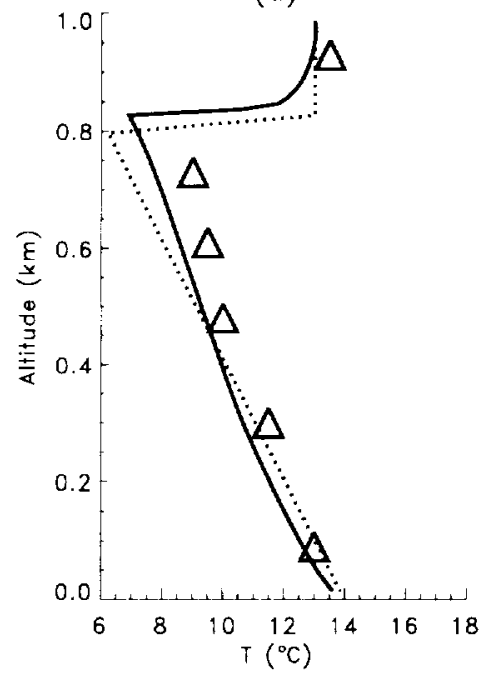

(c)

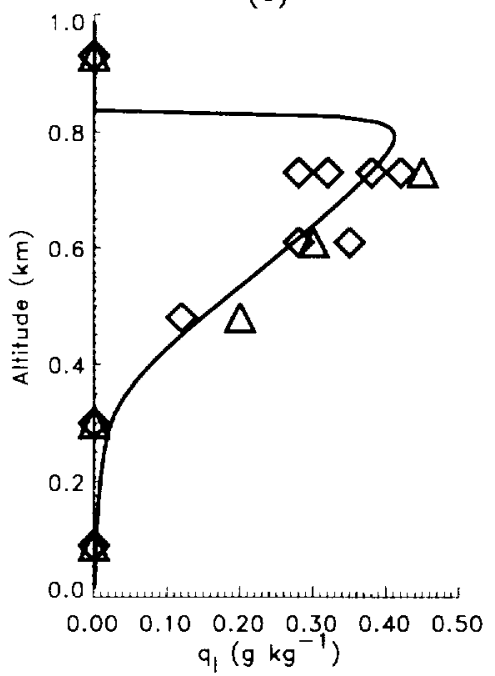

(b)

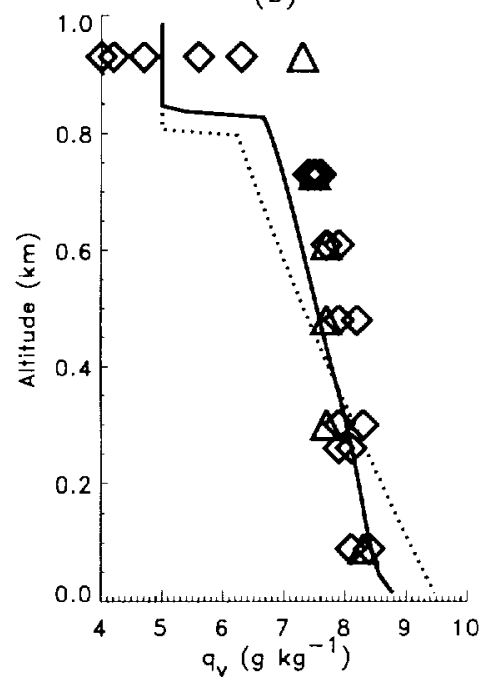

(d)

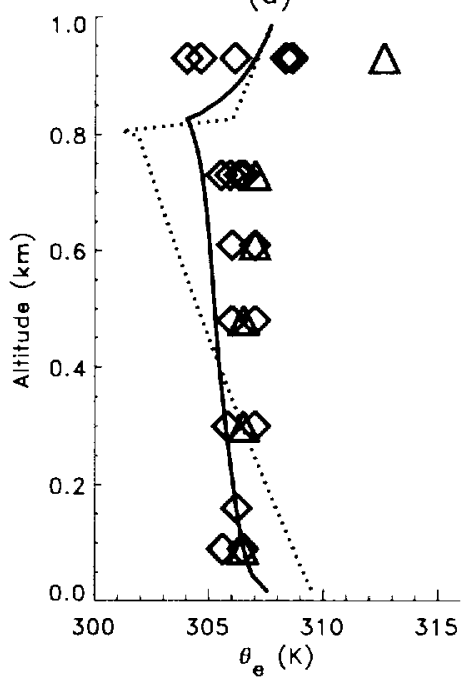

FIG. 3. Comparison between measurements and modeled profiles of (a) $T$, (b) $q_{\mathrm{v}}$. (c) $q_{1}$. and (d) $\theta_{c}$. The dotted line is the initialization and the solid line the model output at $12 \mathrm{~h}$. The triangles are N84's measurements at 1100 LST and the diamonds horizontal flight-leg averages.

drives the boundary layer beyond thermodynamic equilibrium by transporting heat and vapor upward into the cloud layer. The shock of cloud formation is seen in the turbulence, which peaks at $2 \mathrm{~h}$ (Fig. $2 \mathrm{c}$ ); this is followed by a peak in optical depth $\sim 1 \mathrm{~h}$ later, and then a maximum in $q_{1} \sim 1 \mathrm{~h}$ after that. The accumulation of $q_{1}$ produces drizzle, which depletes the cloud layer of liquid water. As the drizzle evaporates below cloud base, the subcloud layer stabilizes with respect to the cloud layer, thereby reducing the supply of vapor and driving the boundary layer back below thermodynamic equilibrium. As the sun rises and the cloud ab- sorbs solar radiation, longwave cooling from cloud top is offset, leading to a reduction in mixing between the cloud and the subcloud layer, and a gradual decline in optical depth by $12 \mathrm{~h}$ (local noon).

\section{(i) Temperature, bulk water, and wind}

Figure 3 shows that during $12 \mathrm{~h}$ of evolution the thermodynamic profiles of the simulated cloud-topped boundary layer evolve toward those measured by N84. The differences between the model results and the measurements are generally within the measurement un- 
certainties [ the only reported estimates of uncertainties for thermodynamic measurements were made by Nicholls and Leighton ( 1986 ) for cloud-top jumps: $\pm 1.0 \mathrm{~K}$ for potential temperature and $\pm 0.5 \mathrm{~g} \mathrm{~kg}^{-1}$ for total water mixing ratio]. The simulated cloud layer has a peak $q_{1}$ that is $\sim 20 \%$ less than the average cloud-top value reported for the N84 measurements by Nicholls and Leighton $\left(0.53 \mathrm{~g} \mathrm{~kg}^{-1}\right)$. The lapse rate throughout the boundary layer that is predicted by the model is less stable than the observations. Because supersaturations predicted by the model are only slightly below zero in the lower region of the cloud, the lower temperatures in the model produce less vapor above cloud base (measured to be $380 \pm 80 \mathrm{~m}$ ) than in the measurements, which enhances differences between modeled and measured $\theta_{\mathrm{e}}$ values. Below cloud base, both $q_{\mathrm{v}}$ and $\theta_{\mathrm{e}}$ are better mixed in the measurements than in the model results. The large variability above cloud top in the measured values of $q_{v}$ and $\theta_{e}$ is due to a strong vertical gradient in vapor.

No wind profiles were given by $N 84$, but the winds were reported as $\sim 8.5 \mathrm{~m} \mathrm{~s}^{-1}$ from the north at all levels. Wind variation across the inversion was reported as small and variable. In the model results, variations in horizontal wind components across the inversion are $<1 \mathrm{~m} \mathrm{~s}^{-1}$. The modeled winds are approximately 9.2 $\mathrm{m} \mathrm{s}^{-1}$ from the north through the cloud layer. Draginduced shear near the surface results in a northerly component of $6.5 \mathrm{~m} \mathrm{~s}^{-1}$ and an easterly component of $0.9 \mathrm{~m} \mathrm{~s}^{-1}$ at the midpoint of the lowest grid layer (15$\mathrm{m}$ altitude ).

\section{(ii) Cloud microstructure}

Figures 4 and 5 show that the microphysical properties of the simulated cloud layer at $12 \mathrm{~h}$ generally match the measurements. No estimates of statistical uncertainties for the microphysics measurements were reported by N84, although some estimates of instrumental uncertainties and systematic errors were presented. The measured vertical distribution of the total number concentration of droplets ( $\left.N_{\text {drops }}\right)$, taken from averages over flight profiles presented by Nicholls and Leighton (1986), is roughly constant with height, with an average of $90 \mathrm{~cm}^{-3}$ (Fig. $4 \mathrm{a}$ ). There is some ambiguity regarding the smallest measured particle sizes: in N84 and Nicholls and Leighton (1986) the radius range is given as $1-400 \mu \mathrm{m}$, while in Nicholls (1987) the same particle data are referred to as having a lower radius cutoff of $2 \mu \mathrm{m}$. Our modeled profile corresponding to the total number of haze particles ( $C N$ transformed to their equilibrium sizes, as used in the radiative calculations ) and droplets larger than $0.9-\mu \mathrm{m}$ radius matches the measurements, although there is a trend of decreasing number with altitude that is not present in the measurements. This trend with height is sensitive to the particle size cutoff, as evident in the dotted line in Fig. $4 \mathrm{a}$ for which the radius cutoff is $2.2 \mu \mathrm{m}$ : the number of droplets increases with height. For the larger particle size cutoff, the profile of droplet concentration correlates with the supersaturation profile in the cloud layer (Fig. 4c). While it is often observed that in marine stratiform clouds the number of droplets is constant with height (e.g., Slingo et al. 1982; Noonkester 1984; Nicholls and Leighton 1986), in our model results the trend is determined by the profile of large, unactivated haze particles (but our results are affected by a supersaturation profile that may be unrealistic, as discussed below ). Noonkester ( 1984 ) used a lower droplet radius cutoff of $0.23 \mu \mathrm{m}$, thereby ensuring that unactivated haze particles were counted. The prediction by our model of large, unactivated haze particles above cloud base is supported by the measurements of Akagawa and Okada (1993), who found high concentrations of small droplets $(r<2.5 \mu \mathrm{m}$ ) near the base of stratus clouds. However, the height dependence of droplet concentration and its sensitivity to the particle size cutoff may also be artifacts of our 1D model.

Average droplet sizes are reported by Nicholls and Leighton ( 1986 ) through the radius of the mean droplet volume, $\tilde{r}_{\mathrm{v}}=\left[3 q_{1} /\left(4 \pi N_{\text {drops }}\right)\right]^{1 / 3}$. Because it is not weighted by the size of the droplets, $\tilde{r}_{\mathrm{v}}$ is sensitive to the number of small droplets (unlike the volume- and area-weighted mean radii). Because $N_{\text {drops }}$ was observed to be roughly constant, and $q_{1}$ increases with height in cloud, $\tilde{r}_{v}$ was observed to increase with height (Fig. 4b). An increase of droplet size with height can be derived from updraft parcel models in which only growth by condensation is treated (e.g., chapter 13 of Pruppacher and Klett 1978). Our model, which represents averages over both updrafts and downdrafts and treats droplet coalescence, closely matches the measured profile of $\tilde{r}_{\mathrm{v}}$ when the radius cutoff is taken to be $0.9 \mu \mathrm{m}$. The agreement is not as good when the radius cutoff is $2.2 \mu \mathrm{m}$, although the tendency with height remains.

The modeled profile of supersaturation $(S)$ at $12 \mathrm{~h}$ (Fig. $4 c$ ) is peaked at cloud top, where it has a value of $0.037 \%$. This peak supersaturation is lower than previous estimates for stratiform clouds, which are $\sim 0.2 \%$ (Hudson 1983); this is consistent with the expected underestimate of peak supersaturation due to averaging over updrafts and downdrafts in our model ( see section $3 \mathrm{c}$ ). The increase of $S$ with height in the cloud layer can be explained by considering the flux of $q_{v}$ ( see below ) from an Eulerian viewpoint. There are significant upward vapor fluxes due to turbulent diffusion at all levels within the boundary layer, but there is virtually no turbulent transport across the inversion. Therefore, vapor tends to accumulate just below the inversion, where it produces a peak in $S$. Furthermore, the peak in radiative cooling of the air at cloud top (due to the maximum in the longwave radiative flux divergence at that altitude - see below) also contributes to the peak $S$ at cloud top. A consequence of this height dependence of $S$ in the cloud layer is that smaller $\mathrm{CN}$ will 
(a)

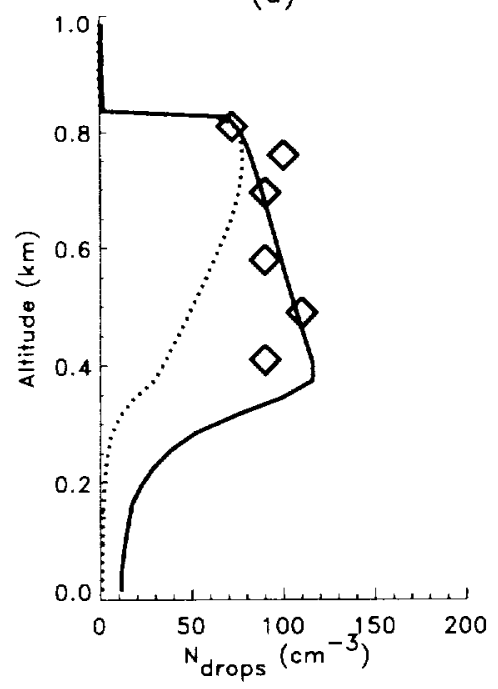

(c)

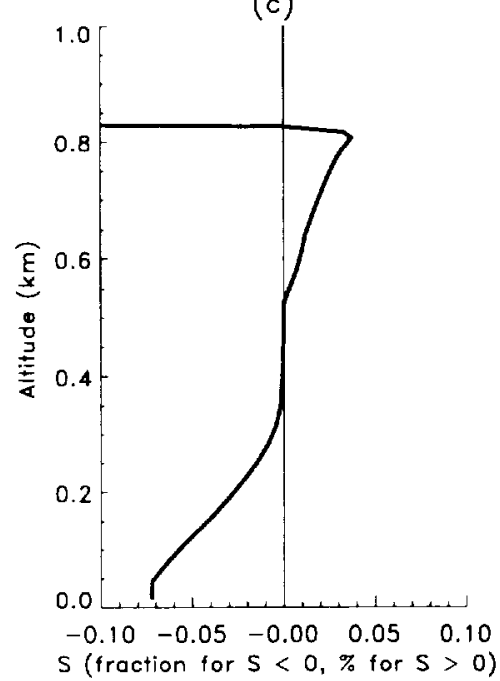

(b)

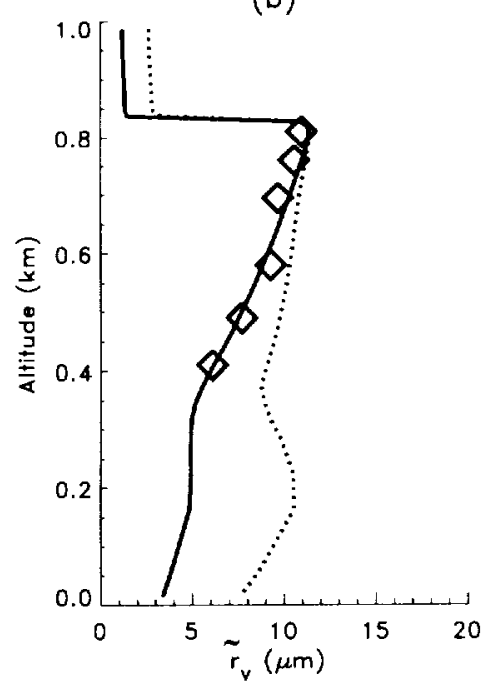

(d)

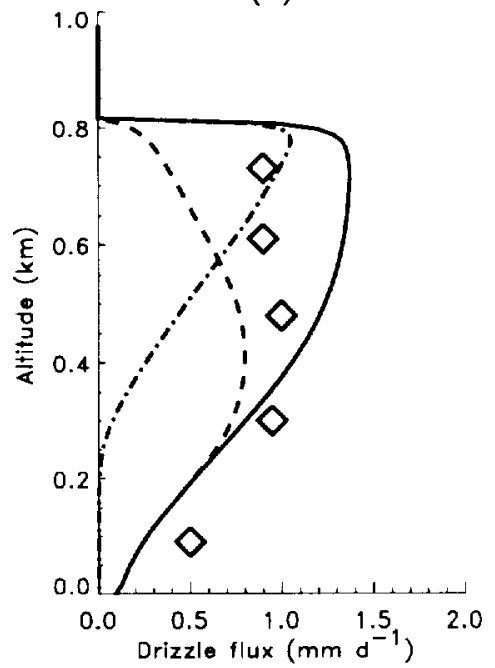

FIG. 4. Comparison between modeled profiles of (a) total number concentration of droplets $\left(N_{\text {drups }}\right)$ and (b) radius of mean droplet volume $\left(\tilde{r}_{v}\right)$ at $12 \mathrm{~h}$ (dotted and solid lines are for radius cut offs of 2.2 and $0.9 \mu \mathrm{m}$, respectively) and profile-average measurements from Nicholls and Leighton (1986) (diamonds). The $\mathrm{CN}$ are included at their equilibrium sizes, as used in the radiative calculations. (c) Modeled supersaturation $(S)$ profile at $12 \mathrm{~h}$ (note the scale change at $S$ $=0)$. (d) Comparison between measured drizzle flux profile from N84 (diamonds) and model results (solid line is total, dash-dotted line is for droplets with $r<25 \mu \mathrm{m}$, and dashed line is for $r>25 \mu \mathrm{m}$ ).

nucleate droplets near cloud top rather than at cloud base, leading to increasing numbers of activated droplets with altitude (correlating with the profile of droplet concentration with a radius cutoff of $2.2 \mu \mathrm{m}$ ). Here $S$ is slightly negative between 520 and $380 \mathrm{~m}$ altitude, below which it steadily diminishes to a value of nearly -0.07 in the lowest model layer, corresponding to a relative humidity of $93 \%$ ( the relative humidity is fixed at $98.3 \%$ in the surface skin layer).

The profile of average supersaturation within the cloud layer predicted by our model (which averages over updrafts and downdrafts) differs from that given by updraft parcel models, which typically predict peak supersaturations near cloud base. In Hall's (1980) 2D 

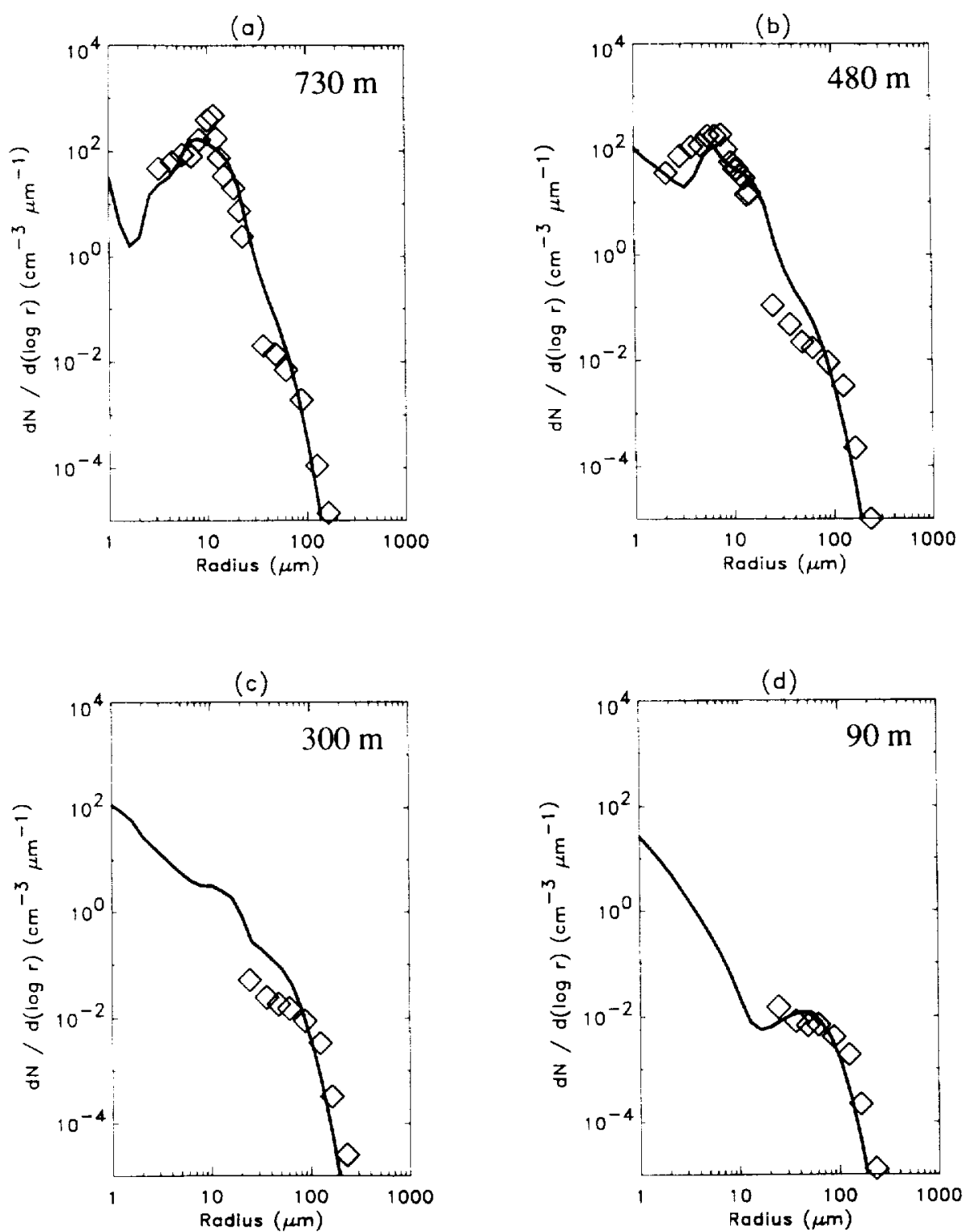

Fig. 5. Comparisons of measured droplet size distributions from horizontal fight averages in N84 (diamonds) and model results at $12 \mathrm{~h}$ (solid lines) at altitudes of (a) $730 \mathrm{~m}$. (b) $480 \mathrm{~m}$, (c) $300 \mathrm{~m}$, and (d) $90 \mathrm{~m}$. The $\mathrm{CN}$ are included at their equilibrium sizes, as used in the radiative calculations.

model simulation (with explicit microphysics) of a warm, convective maritime cloud, maximum supersaturations were predicted near cloud top, as well as near cloud base. Peak supersaturations near cloud top are also predicted by stratocumulus cloud modeling results from 3D large-eddy simulations with explicit microphysics (Kogan et al. 1994). However, in contrast to our model results, Kogan's stratocumulus model predicts supersaturations (in updrafts) that peak near cloud base and decline upward (until the inversion is approached). We will consider some consequences of the horizontal averaging done by our model in section $3 \mathrm{c}$.
Figure 5 compares the modeled size distributions of droplets and haze with horizontal flight leg averages measured by $\mathrm{N} 84$ at four different altitudes. Considering the uncertainties in the measurements and the seven orders of magnitude in droplet concentrations, the model results and the measurements are in surprisingly good agreement at all altitudes. There are peaks in the modeled size distributions due to haze particles ( $r \sim 1 \mu \mathrm{m}$ ) that did not fall within the measurement range. Near cloud top $(730 \mathrm{~m})$ the peak in droplet number at $r=10 \mu \mathrm{m}$ is not as pronounced in the model results as it is in the measurements. In the lower region 
of the cloud $(480 \mathrm{~m})$, the model underpredicts the number of small droplets $(r<10 \mu \mathrm{m})$. The model underpredicts the droplet concentrations in the tail of the distribution $(r \geqslant 100 \mu \mathrm{m})$ at all altitudes. At all altitudes above $90 \mathrm{~m}$, the model overpredicts the number of droplets with radii between 20 and $60 \mu \mathrm{m}$. In another comparison with these measurements, the steady-state model of drizzle production used by Nicholls (1987) also consistently overpredicted the concentrations of droplets with radii between 25 and $60 \mu \mathrm{m}$. However, as noted by $\mathrm{N} 84$, droplets of radius between 20 and 60 $\mu \mathrm{m}$ were severely undercounted in the measurements, so the discrepancy may be the result of a measurement error.

The drizzle flux, defined by

$$
\text { drizzle }=\frac{4 \pi}{3} \rho_{w} \int_{r_{\min }}^{r_{110 i x}} v_{f}\left(r^{\prime}\right) C\left(r^{\prime}\right) r^{\prime 3} d r^{\prime}
$$

and calculated by $\mathrm{N} 84$ from the measured droplet size distributions shown in Fig. 5, is compared to that predicted by our model in Fig. $4 \mathrm{~d}$. The modeled flux is up to $50 \%$ larger than that measured, but the measured fluxes are only accurate to $\pm 40 \%$ (Turton and Nicholls 1987). The flux falls off rapidly below the supersaturated region, resulting in fluxes smaller than the measurements below $300-\mathrm{m}$ altitude. For the model results shown in Fig. 4d, the drizzle flux is broken down into contributions from droplets of radii smaller and larger than $25 \mu \mathrm{m}$. As in the measurements (for which the drizzle flux by droplet size is not shown here), the drizzle flux is dominated by droplets $<25 \mu \mathrm{m}$ in radius in the top $\sim 200 \mathrm{~m}$ of the cloud layer, while at lower altitudes larger drops dominate the drizzle flux.

\section{(iii) Radiative transfer}

It can be seen from Fig. 6 that the radiative profiles of the modeled boundary layer at $12 \mathrm{~h}$ are within the uncertainties of the measurements (N84 estimated the measurement error of solar fluxes to be $\pm 20 \mathrm{~W} \mathrm{~m}^{-2}$ ). Nicholls and Leighton measured an average broadband solar albedo above cloud top of 0.62 (they corrected all their solar fluxes to correspond to a zenith angle of $35^{\circ}$ ). Our model predicts a value of 0.61 at $1-\mathrm{km}$ altitude. While this agreement is surprisingly good, the model overpredicts the amount of downwelling solar flux below $\sim 600$-m altitude (Fig. 6a). This difference in flux is consistent with the underprediction of small droplets $(r<10 \mu \mathrm{m})$ in this region. The model slightly overpredicts the downwelling solar flux above the cloud; this may be due to underestimated columns of ozone and/or water vapor in the overlying model atmosphere (climatological values were used for both).

The "measured" longwave fluxes shown in Fig. 6b are actually theoretical calculations based on measured microphysical and thermodynamic profiles made by N84; Nicholls and Leighton (1986) considered these to be more reliable than the direct measurements due to a systematic error in the radiometer calibration above cloud. Furthermore, the radiometer for measuring upwelling longwave fluxes failed. The difference between the modeled and "measured" upwelling longwave flux near the surface could be due to a lower sea surface temperature assumed by Nicholls and Leighton than we used.

The modeled boundary layer absorbs $53 \mathrm{~W} \mathrm{~m}{ }^{2}$ of solar radiation, and loses $65 \mathrm{~W} \mathrm{~m}^{-2}$ of longwave radiation, yielding a net loss of $12 \mathrm{~W} \mathrm{~m}^{-2}$. For the measured profiles shown in Fig. 6a, $80 \mathrm{~W} \mathrm{~m}^{-2}$ of solar radiation are absorbed, and $79 \mathrm{~W} \mathrm{~m}^{2}$ of longwave radiation are lost between $90-$ and $930-\mathrm{m}$ altitude, yielding a net gain of $1 \mathrm{~W} \mathrm{~m}^{-2}$. The difference between our model predictions and the measurements is principally attributable to the underpredicted solar extinction in the middle of the modeled cloud layer. A result of this difference in the net radiative budget of the boundary layer is that temperatures (and, hence, water vapor mixing ratios) in the cloud layer are below the observed values (Fig. 3 ).

The modeled profiles of radiative heating are also shown in Fig. 6. Net radiative cooling at cloud top is limited to a region $\sim 50 \mathrm{~m}$ deep in the model, while flux profiles calculated by N84 indicate that cooling is restricted to a region $30 \mathrm{~m}$ deep. Net cooling at cloud top drives mixing by destabilizing the cloud layer itself, and also by destabilizing the cloud layer with respect to the subcloud layer. In our model results, solar heating primarily offsets the longwave cooling at cloud top. As mentioned above, less solar heating was predicted by the model than was measured, and the difference occurs primarily in the lower region of the cloud layer. Because solar heating in this region can stabilize the cloud with respect to the subcloud layer, and thereby diminish mixing between the layers, the comparative lack of solar heating in our model allows greater mixing than was measured between the cloud and subcloud layers ( see below).

\section{(iv) Turbulence}

The measured turbulence profiles (for which no measurement uncertainties were reported) are generally reproduced by the model results at $12 \mathrm{~h}$ (Figs. 7 and 8 ). Shown in Fig. 7a is the measured profile of $E$, taken from 2.6-km segments of N84's 1100 LST descent, which finished in the least convective part of the observational area; $E$ was not reported for the horizontal leg averages, so it is not clear how representative these measurements are. Compared to the data, our model overpredicts the peak value of $E$ by $\sim 100 \%$ in cloud and by $\sim 50 \%$ near the surface. The observations show a decrease downward from $400 \mathrm{~m}$ (the observed cloud base during that descent ) to a minimum at 200 $\mathrm{m}$, while the model predicts a decrease downward from $700 \mathrm{~m}$ to a minimum at $300 \mathrm{~m}$. As shown in the $E$ budget (Fig. 7b), turbulence is driven by the buoyancy 
(a)

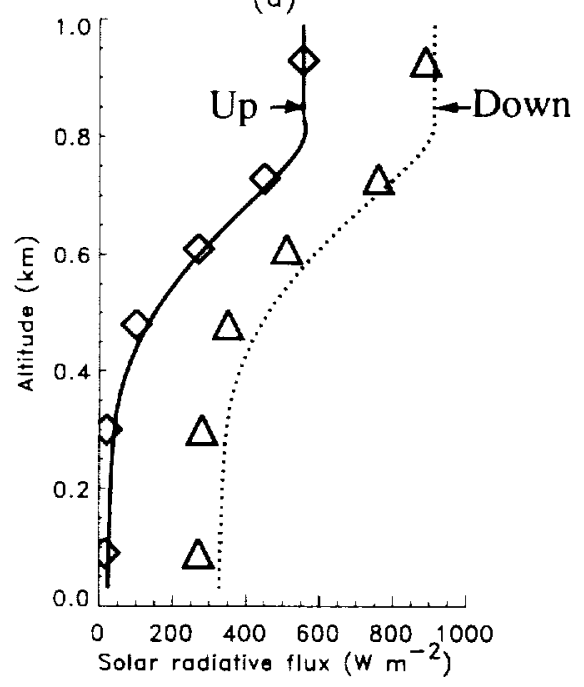

(c)

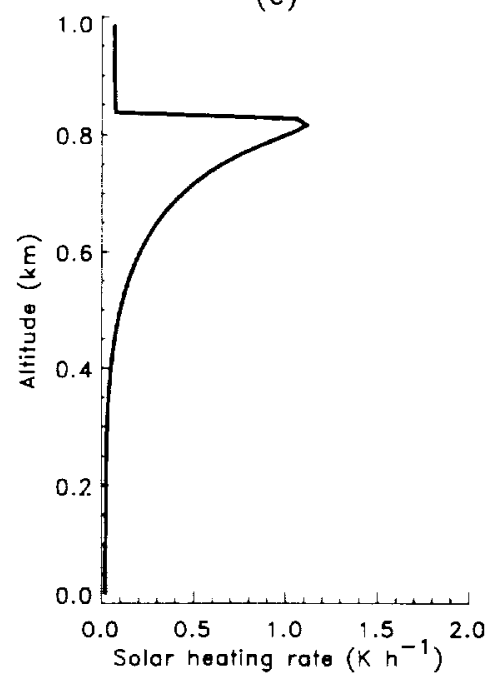

(b)

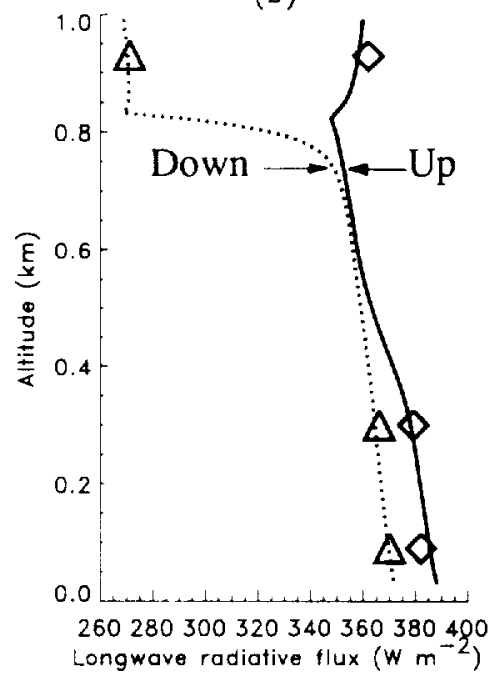

(d)

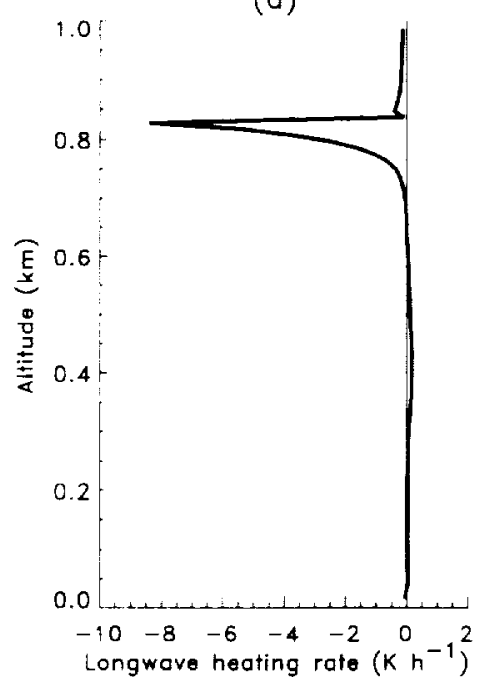

FIG. 6. Measured (a) solar and (b) longwave radiative fluxes from N84: diamonds and triangles are upwelling and downwelling values, respectively. Solid lines are upwelling model results, and dotted lines are dowawelling model results (at $12 \mathrm{~h}$ ). (c) and (d) The modeled solar and longwave heating profiles, respectively.

flux in cloud, where it is offset by dissipation and transport. Both shear and transport produce turbulence just below the cloud, while near the surface, turbulence is driven by shear and buoyancy. A measured budget of $E$ that resembles the modeled budget is presented by N84 (not shown here). However, the measurements indicate a region of buoyant consumption of $E$ below cloud base that is not represented in the model results. Comparison with N84 is complicated because, according to Duynkerke and Driedonks ( 1987), the measured transport term does not include pressure-velocity correlations.
The buoyancy flux is the turbulent flux of $\theta_{v}$. which is a variable that is not conserved under saturated conditions due to phase changes of water. As discussed in section 2, the buoyancy flux is calculated by using a fractional condensation weighting factor to combine the flux from gradient transfer of $\theta_{v}$ with the flux derived through a saturation condition. This weighting factor, which represents the fraction of air that is saturated, is shown in Fig. 7c. It is seen to hover near $100 \%$ in the top $\sim 200 \mathrm{~m}$ of the cloud layer, fall off gradually to $\sim 60 \%$ just above $300-\mathrm{m}$ altitude, and drop off more rapidly below 

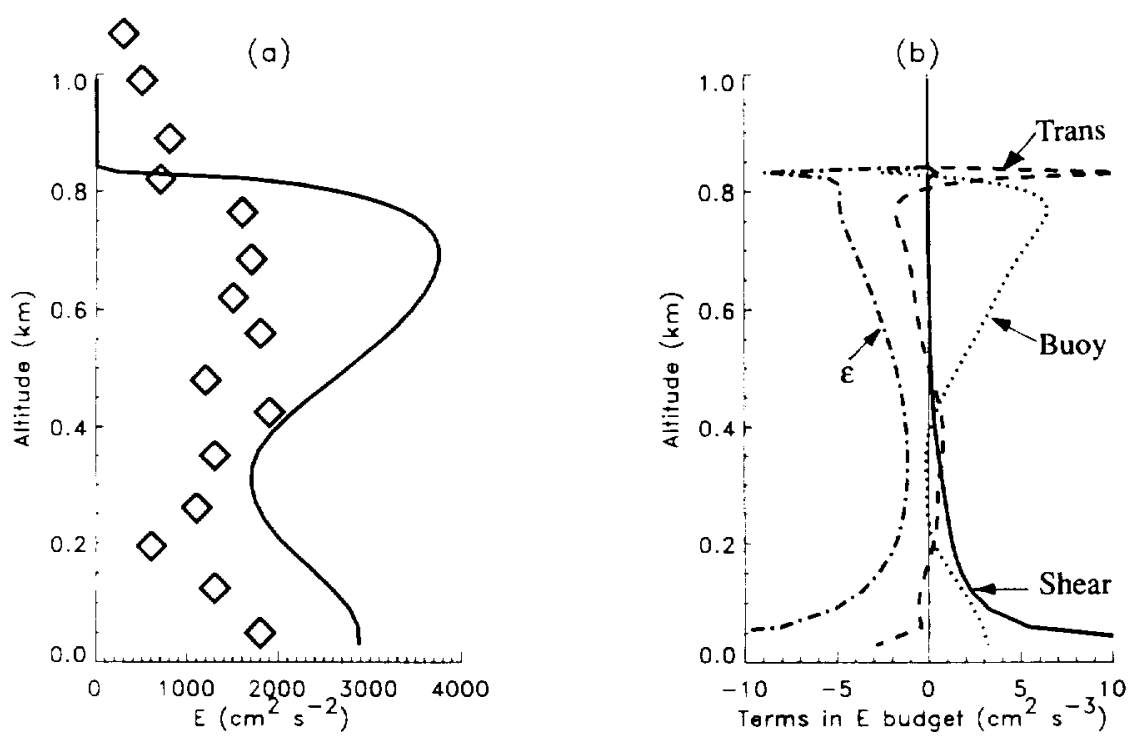

(c)
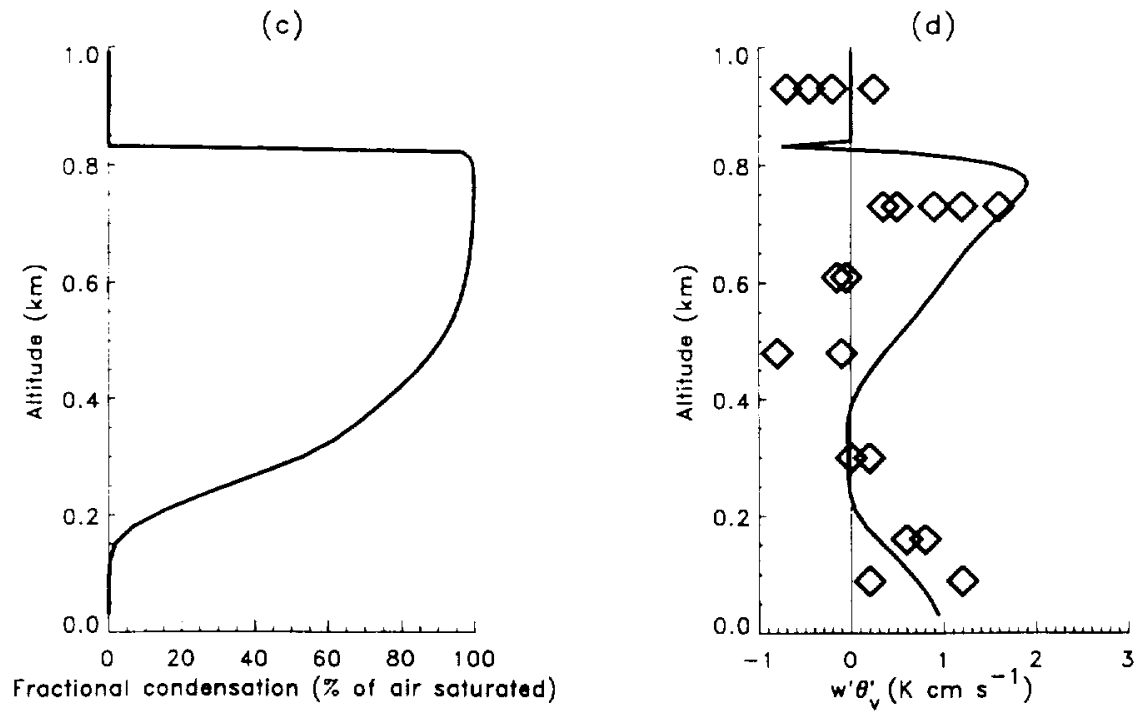

FIG. 7. (a) Comparison of measured $E$ profile from N84 at 1100 LST (diamonds) and model results at $12 \mathrm{~h}$ (solid line). (b) Modeled $E$ budget (solid line is SHEAR, dotted line is BUOY, dashed line is TRANS, and dash-dotted line is $\epsilon$ ). (c) Fractional condensation weighting factor. expressed as a percentage. (d) Comparison of measured turbulent buoyancy fluxes from N84 horizontal flight averages (diamonds) with modeled profile at $12 \mathrm{~h}$ (line).

$300 \mathrm{~m}$, where $S$ starts to decrease dramatically (Fig. 4c).

Figure $7 \mathrm{~d}$ shows the buoyancy fluxes measured during horizontal flight legs and the values predicted by our model at $12 \mathrm{~h}$. The model predicts a general trend with altitude that is consistent with the measurements, but predicts positive values over too deep of a region, consistent with the larger values of $E$ predicted by the model. From the horizontal flight segments, N84 presented measurements of the com- ponents of the buoyancy flux; these are compared to the modeled components in Fig. 8. The modeled turbulent fluxes in Fig. 8 are calculated by combining the unsaturated fluxes (from gradient transfer) and the saturated fluxes (from Eqs. (B3) - (B5) given in appendix B) with the saturation weighting factor used for the buoyancy flux ( see appendix B). Near cloud top the sensible heat flux is overpredicted by the model; in the lower half of the cloud layer the fluxes of water are also overpredicted. 
(a)

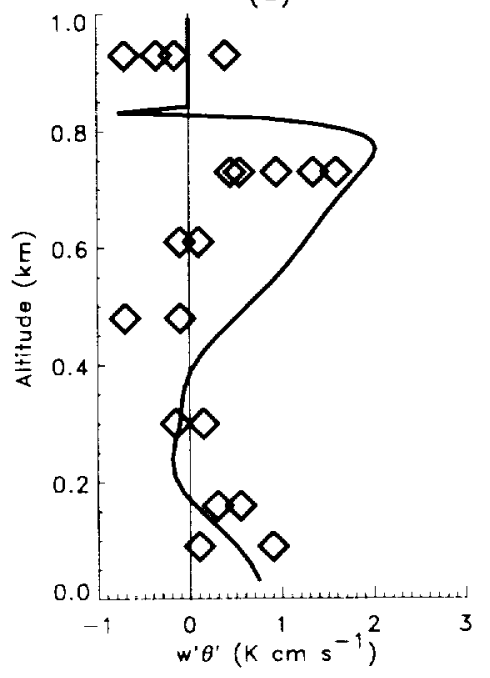

(b)

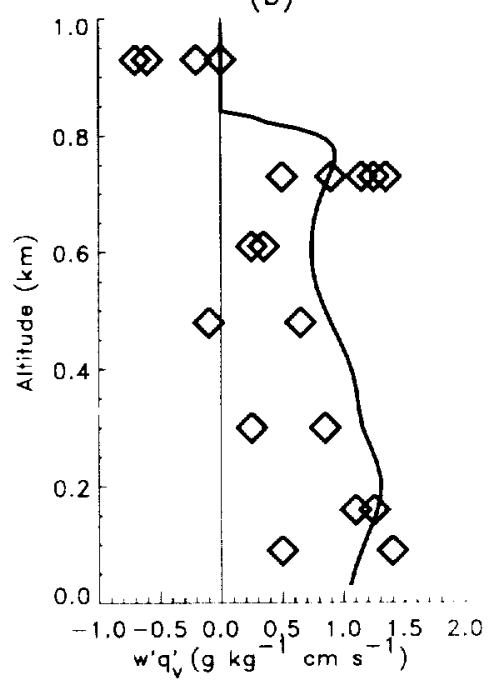

(c)

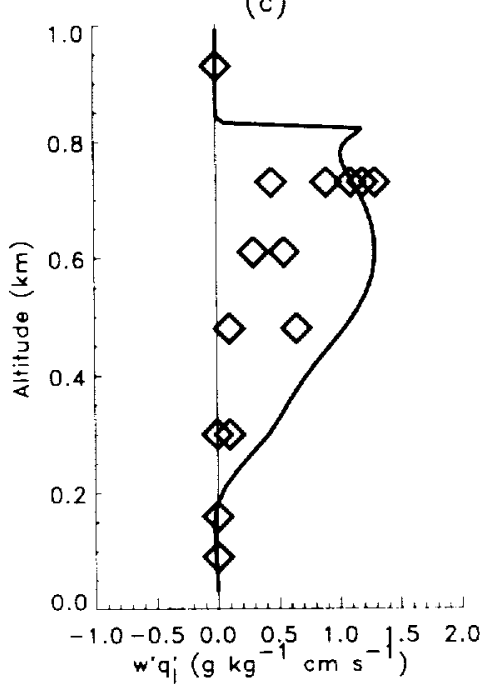

Fici, 8. Comparisons of measured turbulent fluxes of (a) $\theta$, (b) $q_{\mathrm{s}}$, and (c) $q_{1}$ from horizontal flight averages in N84 (diamonds) with modeled profiles at $12 \mathrm{~h}$ (lines).

\section{(v) Summary}

The results presented above show that some of the features of the stratocumulus-topped marine boundary layer predicted by the model are in agreement with the measurements of $\mathrm{N} 84$, but that some features are not as well reproduced by the model. The bulk thermodynamics of the boundary layer and the profile of the drizzle flux are generally reproduced by the model, as are the radiative fluxes in the upper region of the cloud. The model slightly underpredicts the concentration of 10- $\mu \mathrm{m}$ radius droplets near cloud top, and it underpredicts the number of droplets $<10-\mu \mathrm{m}$ radius in the lower region of the cloud. This lack of small droplets is responsible for the comparative lack of solar extinction in the lower region of the cloud. A lack of solar absorption is consistent with slightly lower temperatures in the cloud layer and greater mixing with the subcloud layer in the model results than in the measurements. Further reasons for discrepancies between the measurements and the model results are considered in section 3c.

\section{b. Comparisons with measurements of Nicholls and Leighton (1986)}

We will now compare results from simulations using the model described in this paper with two sets of airborne measurements taken in stratiform clouds over the North Sea by Nicholls and Leighton (1986), hereafter referred to as NL. The first set of measurements from NL (flight 564 made on 15 December 1982) provides a good test of the versatility of the model because the turbulence was quite different from that in flight 526, which we have compared to model results in section 3a. In fight 564, gale conditions produced a cloud that nearly filled the depth of the boundary layer $1670 \mathrm{~m}$ deep cloud in an 850-m boundary layer). In contrast, in flight 526 cloud-top radiative cooling produced the buoyancy that drove mixing in a boundary layer that was only half filled by the cloud layer. In the second dataset from NL ( flight 528 made on 29 July 1982), a thin cloud layer (depth $190 \mathrm{~m}$ ) capped a deep boundary layer $(1260 \mathrm{~m})$, resulting in a greatly reduced drizzle flux. Since NL presented significantly less detailed data than N84, the comparisons with model results will be less comprehensive than presented above. Our main objective is to show that the model responds to significant variations in boundary conditions in a manner consistent with observations.

\section{1) Flight 564 (Shear-driven stratus)}

In flight 564 the measured average wind speed was $27 \mathrm{~m} \mathrm{~s}^{-1}$. The cloud top was smooth and featureless; NL classified it as stratus, compared to stratocumulus for the other cases they studied that exhibited cellular patterns associated with convective motions. The different appearances of the clouds reflects the different processes that produced the turbulent mixing. In modeling this dataset, Duynkerke and Driedonks (1988) found that the large drizzle fluxes produced by the thick cloud in flight 564 had a significant effect on the vertical structure of the cloud layer.

Shown in Table 1 are the boundary and initial conditions used for the model simulations of flight 564 . The divergence rate was increased in this model simulation to prevent upward growth of the boundary layer due to increased shear-driven turbulence. Because the observations of flight 564 were made in December 
TABL \&: 1. Summary of (a) boundary conditions and (h) initial conditions for model simulations. Flight 526 corresponds to the base case simulation; flights 564 and 528 correspond to the additional model simulations presented in section $3 \mathrm{~b}$. In flight 564 , a distribution of $\mathrm{CN}$ (representing sea salt) is fixed in the lowest model layer, as described in the text.

\begin{tabular}{ccccc} 
& \multicolumn{2}{c}{ Flight } \\
\hline Parameter & 526 & 564 & 528 \\
\hline
\end{tabular}

(a) Boundary conditions

Geostrophic wind speed $\left(\mathrm{m} \times{ }^{\prime}\right)$

Divergence rate of horizontal wind velocity (s ')

Sea surface temperature $\left({ }^{\circ} \mathrm{C}\right)$

Temperature above inversion $\left({ }^{\circ} \mathrm{C}\right.$ )

Vapor mixing ratio above inversion ( $\mathrm{g} \mathrm{kg} \mathrm{')}$

Downwelling longwave flux above inversion ( $\mathrm{W} \mathrm{m}^{2}$ )

Solar zenith angle at noon ( $\left.{ }^{\circ}\right)$

Production rate of $\mathrm{CN}$ (cm ${ }^{*} \mathrm{~s}^{1}$ )

(b) Initial conditions

Height of inversion (m)

Temperature of lowest model layer $\left({ }^{\circ} \mathrm{C}\right)$

Initial concentration of $\mathrm{CN}(\mathrm{cm}$ )

8.5
$2.5 \times 10^{\circ}$
1.5
1.3
5
270
35
0.018

27

$11 \times 10^{\circ}$

12.5

9.5

6.2

24.5

75

(1)

3.5

$2 \times 10^{6}$

16

13

250

37

0.022

$\begin{array}{lll}800 & 900 & 1250 \\ 14 & 13 & 17 \\ 10(00 & 10 & 1200\end{array}$

(flight 526 was in July), the sea surface and the air above the inversion are colder, and the minimum solar zenith angle is much greater than for flight 526 . Because aerosols in the marine boundary layer during periods of high wind consist mainly of sea salt (e.g., O'Dowd and Smith 1993), and because droplet concentrations measured during flight 526 generally decreased with height (Fig. 9c), for this simulation we did not prescribe a distributed source of sulfate particles throughout the boundary layer, as we did in all the other model simulations. Instead, we fixed a size distribution of sea salt particles in the lowest layer of the model, based on measurements for $17 \mathrm{~m} \mathrm{~s}^{-1}$ wind speeds (O'Dowd and Smith 1993). The fixed distribution in the lowest layer provides $\mathrm{CN}$ to the boundary layer by mixing upward. For the distribution in the lowest layer, we used a total CN concentration of $200 \mathrm{~cm}^{3}$, a geometric mean number radius of $0.2 \mu \mathrm{m}$, and a geometric standard deviation of 2.5 . We also initialized a sulfate distribution with a concentration of $10 \mathrm{~cm}$ throughout the model domain with the same mean size and distribution width as in the base case simulation. Because the dynamic relaxation time for such strong winds is about one day, we started the simulation at noon and ran the model for $27 \mathrm{~h}$ (measurements in flight 564 were between 1100 and 1500 LST).

In the 27-h model simulation, a cloud layer $600 \mathrm{~m}$ deep developed in an $800-\mathrm{m}$ boundary layer (cloud depth in the model is taken to be the difference between the altitudes at which visibility is $\langle 1 \mathrm{~km}$ ). Figure $9 \mathrm{a}$ shows that the model overpredicts the liquid water in the top $200 \mathrm{~m}$ of the cloud Jayer, suggesting that the model underpredicts cloud-top entrainment in this simulation. The broadband solar albedo (above cloud top) of the modeled cloud at noon was $70 \%$, compared to the measured value of $68 \%$. As in the measurements, the vertical mixing in the model was driven primarily by shear, though the model predicted a region of positive buoyancy flux below cloud top that was inconsistent with the measurements (not shown). Although the modeled temperature profile matches the measured profile through most of the depth of the boundary layer (not shown), near cloud top the measured profile was more stable than indicated by the model. The overprediction of the instability of the temperature profile near cloud top indicates that the entrainment of inversion air is underpredicted by the model. The modeled instability is attributable to radiative cooling and results in a positive buoyancy flux. The shape of the modeled wind profile matches the measurements, although the observed jumps at cloud top are underpredicted by the model (Fig. 9b). The increased wind shear at cloud top in the observations resulted in more entrainment of inversion air than in the model, which evaporated more droplets in the upper region of the cloud as well as more completely offsetting radiative cooling ( which was further reduced due to decreased liquid water). This interpretation is supported by comparing modeled and measured droplet concentrations (Fig. 9c): the average number of droplets is captured well by the model, but there is more variation with height in the measurements. The local maximum in droplet concentration for droplets of radius $>0.9 \mu \mathrm{m}$ at $\sim 350-\mathrm{m}$ altitude in the model results is attributable to swollen haze particles (because of the high relative humidity); this is evident because there is no maximum in the concentration of droplets of radius $>2.2 \mu \mathrm{m}$ at that altitude. Finally, comparison of modeled and measured drizzle fluxes (Fig. 9d) shows that the modeled predictions exceed the measurements within the cloud layer. However, the differences are generally within the $40 \%$ uncertainty of the measurements (Nicholls 1987). 
(a)

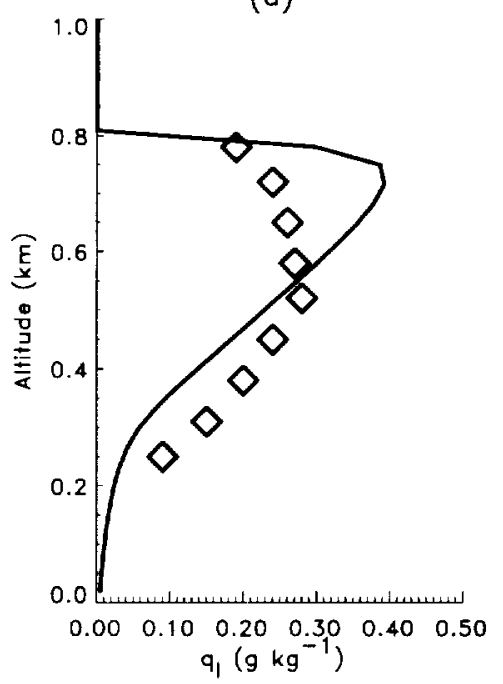

(c)

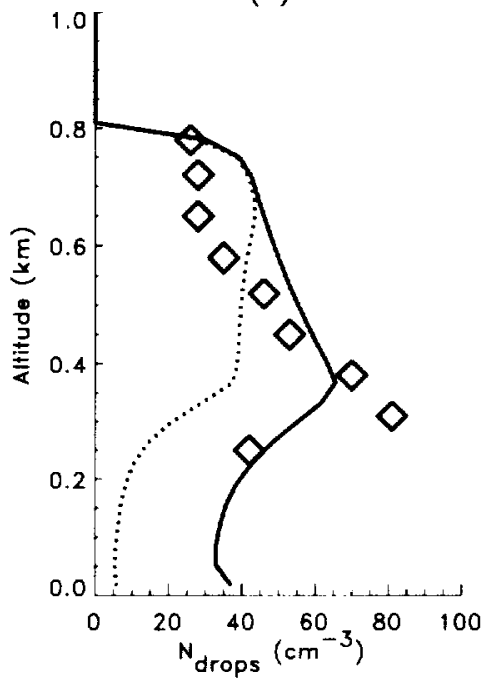

(b)

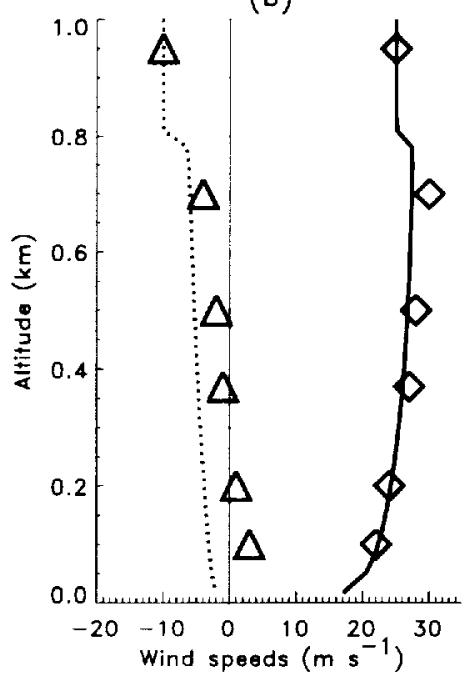

(d)

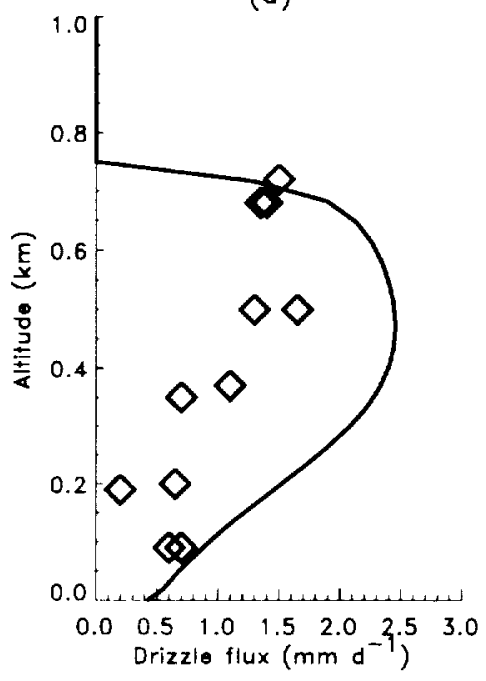

FiG. 9. Comparison between measurements (symbols) from flight 564 (Nicholls and Leighton 1986) and modeled profiles (lines) at $25 \mathrm{~h}$ of (a) $q_{1}$; (b) wind speeds (dotted and solid lines are modeled $u$ and $v$ components, respectively; triangles and diamonds are the measured $u$ and $v$ components, respectively); (c) total number concentration of droplets ( $\left.N_{\text {draps }}\right)$ (dotted and solid lines are model output for radius cut offs of 2.2 and $0.9 \mu \mathrm{m}$, respectively); and (d) drizzle flux (solid line is model output). The measurements in (a), (b), and (d) are horizontal averages, the measurements in (c) profile averages.

In summary, the model simulation for flight 564 reproduces the general features of the measurements: a deep cloud layer driven by wind shear, resulting in large drizzle fluxes. However, entrainment at cloud top was less pronounced in the model than in the measurements.

\section{2) Flight 528 ( high, thin Stratocumulus)}

The cloud layer on flight 528 was measured to be $190 \mathrm{~m}$ deep, atop a boundary layer $1260 \mathrm{~m}$ deep. This thin cloud produced little drizzle. In the measured profiles of $T$ and $q_{v}$ (Figs. 10a and 10b, respectively) and the winds ( not shown), it is seen that the air below 700 $\mathrm{m}$ was strongly decoupled from the overlying air ("decoupled" refers to a lack of vertical mixing between layers). Below $700 \mathrm{~m}$ the temperature profile was stable and the winds stronger. This structure reflects horizontal variations in air properties (the strong wind shear implies different source regions for the air above and below $700 \mathrm{~m}$ ). Although time variations in the pro- 
files of air properties seems likely, no information on time dependence was provided by NL. The structure of the observed boundary layer implies that there was little transport of water vapor from the sea surface to the air above $700 \mathrm{~m}$. To restrict mixing (in the context of a gradient transfer formulation of turbulent fluxes) between the upper and lower regions of the boundary over the 12-h model simulation, water vapor was initialized with a constant mixing ratio of $6.5 \mathrm{~g} \mathrm{~kg}^{-1}$ throughout the boundary layer (at the top of the boundary layer, where this much vapor would have saturated the air, we limited the initial relative humidity to $99 \%$ ). Other initial and boundary conditions are listed in Table 1.

After $12 \mathrm{~h}$ of simulation, the model produces a cloud layer $210 \mathrm{~m}$ deep that caps a boundary layer $1200 \mathrm{~m}$ deep. As seen in Fig. 10a, the model underpredicts the temperatures in the upper region of the boundary layer; in the same region, the model overpredicts the water vapor mixing ratio (Fig. 10b). However, this apparent inconsistency is within the errors of the measurements. Neither the stable temperature profile near the surface nor the enhanced water vapor near the surface are reproduced by the model simulation. As mentioned previously, these features of the profiles probably reflect horizontal variations (which cannot be represented in a 1D model) and/or unmeasured time variations in air properties. The model results closely match the measured liquid water profile (Fig. 10c). There were 140 droplets $\mathrm{cm}^{3}$ measured in the cloud layer, and the model produced a cloud with 150 droplets $\mathrm{cm}^{-3}$. The average broadband solar albedo measured above cloud top was $43 \%$; the modeled value was $40 \%$. Finally, as shown in Fig. 10d, the model simulation resulted in a drizzle flux that was much less than in the other model simulations (Figs. 4d and 9d), yet the measured drizzle flux for flight 528 (albeit only a single data point) was even smaller.

In summary, the model simulations match the measurements of the thin cloud studied in flight 528. More structure was measured in the lower region of the boundary layer than the model indicated, but this difference could have been due to horizontal variations and/or time dependence of the air properties.

\section{c. Likely consequences of $1 D$ model assumptions}

While the model results appear to generally match the measurements within the ranges of measurement uncertainties, it is worth considering the effects of some of the fundamental assumptions made in the model's formulation. Foremost of these assumptions is that in our ID model, grid layers represent averages over updrafts and downdrafts, whereas in a real cloud, the microphysical environment of a downdraft differs from that in an updraft. To the extent that updrafts and downdrafts maintain their identities throughout deep regions of stratocumulus cloud layers (as in cumulus cloud fields ), a $1 \mathrm{D}$ model cannot represent the microphysical environment realistically. However, the 1D model approach is justifiable to the extent that stratocumulus cloud layers are horizontally homogeneous and the microphysical properties are similar in updrafts and downdrafts. Thus, our model results represent the consequences of averaging over updrafts and downdrafts.

Although there are no measurements of supersaturation profiles, numerical cloud models that consider the microphysical environment of updrafts ( such as updraft parcel models and 2D and 3D models) predict peak supersaturations near cloud base within updraft regions. In contrast, our model does not predict a (horizontally averaged) peak supersaturation near cloud base. One consequence is that the model probably underpredicts the condensational growth of some of the droplets in the lower region of the cloud layer (those in supersaturated updrafts, which are not represented in the model), resulting in an underprediction of small droplet concentrations in this region. This interpretation of the discrepancies between the model results and measurements is consistent with the lack of droplets $(r$ $>2.2 \mu \mathrm{m}$ ) near cloud base in the model results in comparison to the measurements (Fig. 4a). Furthermore, overprediction of evaporation in the lower region of cloud probably affects mixing, by destabilizing the lower region of the cloud with respect to the subcloud layer, thereby inducing a buoyancy flux that allows more mixing to occur than was observed, which is consistent with the comparisons with measured turbulent fluxes shown in Figs. $7 d$ and 8.

Although a peak in average supersaturation near cloud top may be physically representative of stratocumulus cloud layers (Kogan 1994), it is likely that there are unsaturated regions in downdrafts near cloud top. In this case, by averaging over updrafts and downdrafts, the model neglects any time spent by droplets near cloud top in unsaturated downdrafts (much as it neglects time spent in saturated updrafts near cloud base). Hence, this model simplification probably results in droplets being exposed to saturated conditions for artificially long durations near cloud top (much as they are exposed to artificially long durations of unsaturated conditions near cloud base). This interpretation of likely model shortcomings is consistent with an underprediction of the peak in the droplet size distribution at $r \sim 10 \mu \mathrm{m}$ near cloud top (Fig. 5a). Artificially enhanced condensation near cloud top could result in overpredicting the drizzle fluxes there, by growing droplets into size ranges where they are more efficiently captured gravitationally by larger drops, consistent with overpredicted drizzle rates near cloud top in all the simulations (Figs. $4 \mathrm{~d}, 9 \mathrm{~d}$, and $10 \mathrm{~d}$ ). In combination with an underpredicted drizzle flux below cloud base, the vertical gradient of drizzle flux is overpredicted, consistent with the comparison against observations (Fig. 4d).

Another likely consequence of averaging over updrafts and downdrafts is that peak supersaturation val- 
(a)

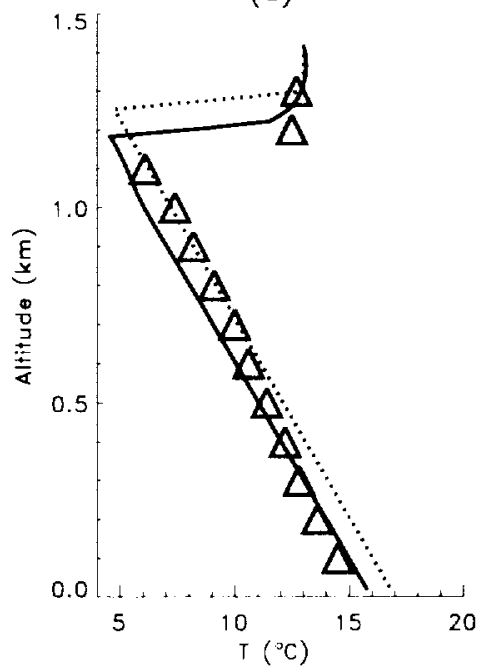

(c)

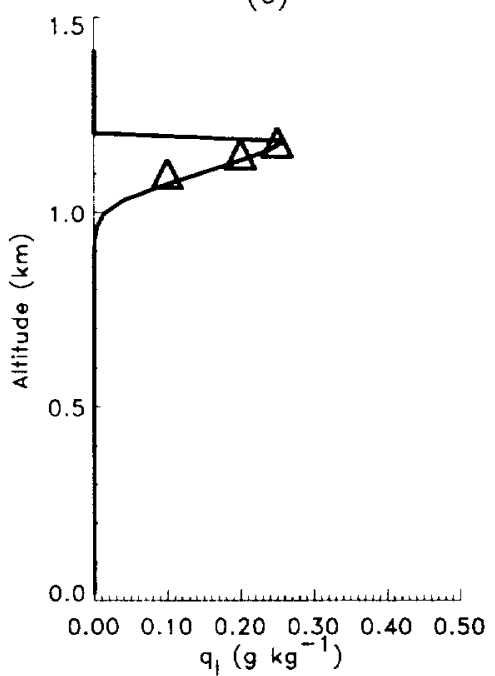

(b)

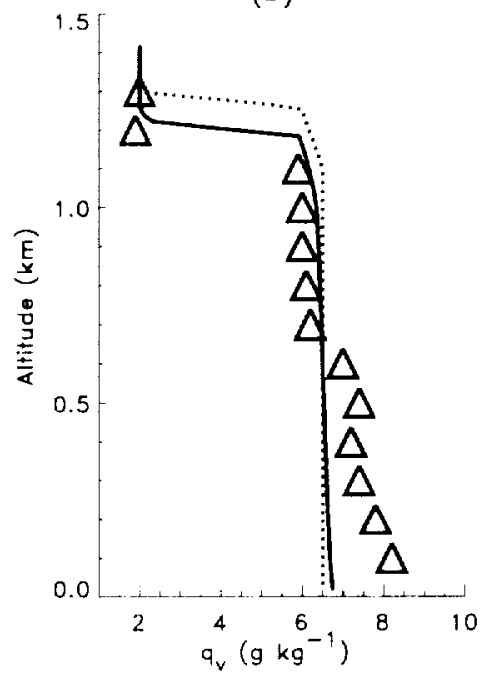

(d)

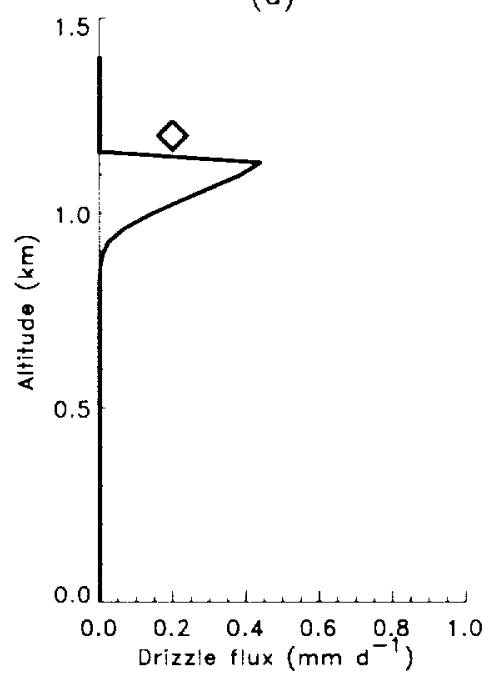

FIG. 10. Comparison between measurements (triangles) from flight 528 (Nicholls and Leighton 1986) and modeled profiles at $12 \mathrm{~h}$ (lines) of (a) $T$, (b) $q_{\mathrm{v}}$, (c) $q_{1}$, and (d) drizzle flux. The dotted lines in (a) and (b) are model initializations. The triangles in (a)-(c) are measurements from a protile at $1130 \mathrm{LST}$, the diamond in (d) is an average cloud-top measurement.

ues are underpredicted by the model, due to the averaging process. Therefore, the model likely underpredicts the fraction of $\mathrm{CN}$ that are nucleated. To compensate for this shortcoming, the total number of $\mathrm{CN}$ input to the model is probably artificially high.

We will now investigate the sensitivity of model outputs to some input parameters and assumptions.

\section{Sensitivity of the model to physical assumptions}

Some of the physical processes represented in our model, such as the radiative effect on the condensa- tional growth of droplets and the scattering of radiation in the infrared, are not generally included in cloud microphysical models. Therefore, we start this section by describing the effects of these processes on model results. This is followed by investigating the sensitivity of the model outputs to the assumed values of the condensational coefficient and the gravitational collection efficiencies, the flux-profile relationships used in the evaluation of surface boundary conditions, the probability distribution function used in the partial condensation scheme, and the treatment of horizontal velocity divergence. For each of the sensitivity tests, the model 
simulation of section $3 a$ ( N84 and flight 526 in NL) is repeated with either a physical process omitted or a parameter changed.

\section{a. Radiative effects on condensational growth of droplets}

Several researchers have evaluated theoretically the effects of radiative heating on the condensational growth of droplets (e.g., Barkstrom 1978; Davies 1985). Caughey and Kitchen (1984) used a parcel model to analyze measured droplet size distributions in a stratocumulus cloud layer and found that the effects of radiative transfer on droplet condensational growth were significant. However, these effects have been generally ignored even in rather sophisticated models of cloud microphysics (e.g., Hall 1980; Flossman et al. 1985; Nicholls 1987). Near the top of a cloud layer, where radiative cooling rates are significant, cloud droplets are cooled relative to the ambient air by radiation. There are two direct effects of such temperature differences on cloud microphysics: increased condensational growth rates and a decrease in $S_{\text {cril }}$. These two processes act in opposite directions on droplet nucleation: the first decreases the supersaturation, thereby decreasing the number of droplets nucleated, while the second increases the number of droplets nucleated.

To investigate the importance of this cloud droplet radiation effect, we ran the model without including the effects of radiative droplet cooling on droplet activation and condensational growth. We will refer to this as the "NO_QRAD" case, to distinguish it from the "base" case described in the previous section. Two direct effects are expected from omitting the effects of radiative heating on droplet condensational growth: decreased condensational growth rates result in increased supersaturation and thereby increase droplet nucleation, while increased values of $S_{\text {crit }}$ decrease droplet nucleation. The differences between the results are pronounced: compared to the base case, in the NO_QRAD case the total number of droplets at cloud top is more than doubled (Table 2). This increase is due to a greater concentration of droplets $<10 \mu \mathrm{m}$ in radius. In the NO_QRAD case, the increase in droplet concentration results from a significant increase in the peak supersaturation. This result implies that, with regard to droplet nucleation, the effect of $q_{\text {rad }}$ on condensational growth dominates the effect on $S_{\text {crit }}$.

Other changes in cloud properties result from the increase in droplet concentration. Smaller average droplet size (as measured by $r_{\text {eff }}$, the area-weighted mean radius, as well as $\tilde{r}_{\mathrm{V}}$ ) leads to less efficient growth of droplets by collection. Because droplet collection is an important sink for droplet number, less efficient collection magnifies the difference in droplet concentration beyond that attributable to droplet activation alone. Decreased droplet collection also results in a nearly $20 \%$ reduction in the peak drizzle rate. Lower drizzle rates allow the peak $q_{1}$ to increase by $24 \%$ in simulation NO_QRAD. The combination of smaller droplets and increased $q_{1}$ leads to a $38 \%$ enhancement in the cloud optical depth and relative increases of $12 \%$ in the broadband solar albedo and $45 \%$ in the peak longwave cooling rate. Greater cooling at cloud-top (an indirect result of omitting the effect of radiative transfer on droplet condensation and nucleation ) enhances vertical mixing, and the inversion height increases twice as much as it does in the base case.

We conclude that in our model droplet radiative transfer has some very important effects on cloud properties. But to the extent that droplets near the top of the cloud experience condensational growth for artificially long time periods (as discussed in section $3 \mathrm{c}$ ), the model likely overestimates the effects of droplet radiative transfer.

\section{b. Infrared scattering}

Infrared scattering is typically ignored in cloud models. To investigate its impact on our model results, we ran a simulation in which infrared scattering was set to zero (NO_IR_SCAT). Without infrared scattering, infrared photons have fewer opportunities to be absorbed by the cloud layer, and are more readily lost to the upper atmosphere. As seen in Table 2, ignoring infrared scattering leads to a $29 \%$ increase in the maximum longwave cooling. Greater cloud-top cooling increases the peak supersaturation sufficiently to activate smaller $\mathrm{CN}$, thereby providing more droplets at cloud top. The increase in droplet concentrations leads to a small decrease in $r_{\text {eff }}$, which causes the drizzle rate to decrease slightly. Decreased drizzle and increased supersaturation allow the peak $q_{1}$ to increase by $10 \%$ over the base case. Optical depth and albedo are also increased.

We conclude that infrared scattering by clouds is important in our model and should require further investigation with other models.

\section{c. Coalescence efficiencies}

The likelihood of droplets combining due to differences in their fall speeds is represented by a matrix of gravitational collection efficiencies. The collection efficiency between two droplets is the product of the likelihood that they collide (the collision efficiency) with the likelihood that their collision results in their merging into a single droplet (the coalescence efficiency). While coalescence efficiencies are often assigned a value of unity (e.g., Hall 1980; Flossman et al. 1985), in our model we employ the parameterization of coalescence efficiencies derived by Beard and Ochs (1984). The smallest values of these efficiencies are for collisions between large droplets, where the coalescence efficiency falls to a value of 0.5 . To investigate the significance of these coalescence efficiencies, we ran a simulation ( $\mathrm{COAL}=1$ ) in which all coalescence efficiencies were assigned a value of unity. 


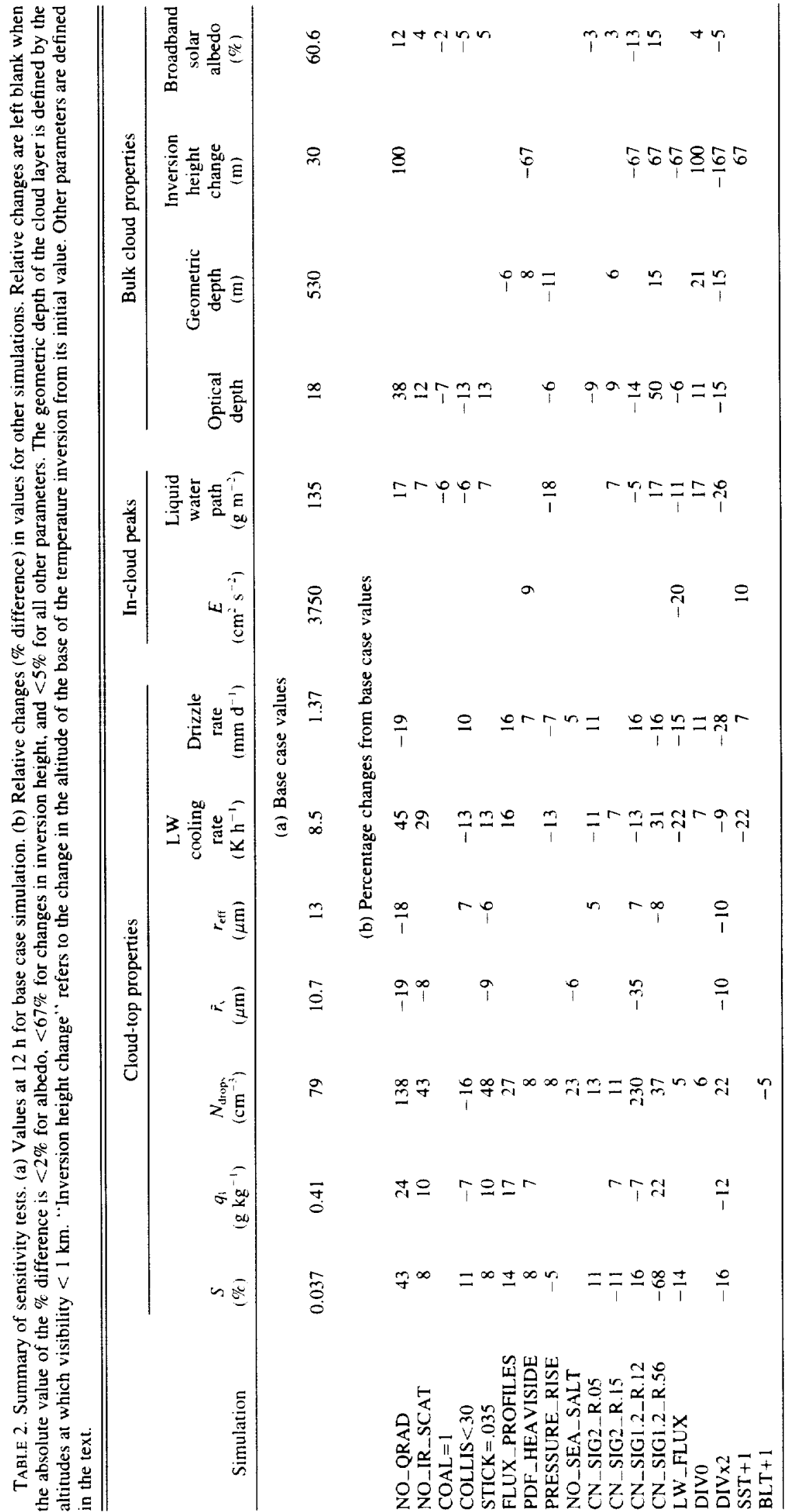


The differences between the COAL $=1$ simulation and the base case are modest (Table 2 ). Near cloud base, where the drizzle flux is dominated by large drops produced from gravitational collection, the drizzle flux for the COAL $=1$ simulation is increased by $\sim 10 \%$ over that in the base case. At the surface, the drizzle flux is increased by $65 \%$ over the base case. Although the peak in $q_{1}$ is unchanged, the liquid water path (the vertical integral of $q_{1}$ ) is reduced, resulting in a reduction of optical depth and small reduction of albedo.

We conclude that realistic coalescence efficiencies should be used, although their effects on the microphysics of stratocumulus clouds are relatively small in our model results.

\section{d. Collision efficiencies of small droplets}

There is some disagreement in the literature regarding the values of the collision efficiencies when both droplets are $<30 \mu \mathrm{m}$ in radius. Hall's (1980) values, which are employed in our base case, were computed by Davis (1972) using Stokesian hydrodynamics. By approximating the effects of fluid inertia, Klett and Davis (1973) calculated increased collision efficiencies. For example, for a $20-\mu \mathrm{m}$ radius droplet colliding with a $10-\mu \mathrm{m}$ radius droplet, Klett and Davis (1973) obtained a collision efficiency that was twice the value calculated by Davis (1972) (13 and $6.8 \%$, respectively ). In simulation COLLIS $<30$ we investigated the sensitivity of our model results to these different collision efficiencies by using the values derived by Klett and Davis ( 1973).

Simulation COLLIS $<30$ reduces the total concentration of droplets (Table 2), and there are more droplets $>20 \mu \mathrm{m}$ in radius at all altitudes below cloud top than for the base case. The increase in larger droplets is reflected in increased drizzle fluxes. For example, at an altitude of $480 \mathrm{~m}$, the drizzle flux increases $20 \%$ over that in the base case, while at the surface there is a $55 \%$ increase in the drizzle flux. Larger drizzle fluxes reduce $q_{1}$. Lower $q_{1}$ and larger droplets (as measured by $r_{\text {eff }}$ ) combine to reduce the optical depth and the peak longwave cooling rate (both by $13 \%$ ), and diminish the albedo (a relative decrease of $5 \%$ ).

We conclude that a change in the collision efficiencies of small droplets by a factor of two has noticeable effects on some of our model results.

\section{e. Condensation coefficient}

The condensation coefficient describes the fraction of water vapor molecules striking the surface of a droplet that actually stick to the droplet. The value of the condensation coefficient is uncertain. For a quasi-quiescent surface, an average value of 0.035 is suggested by Pruppacher and Klett (1978), while the values for a rapidly renewing water surface are larger by an order of magnitude and more. In our base simulation we use a value of 1.0 for the condensation coefficient. To investigate the sensitivity of the model results to this parameter, we ran a simulation in which a condensation coefficient of 0.035 was used (STICK $=.035$ ).

As seen in Table 2, there is nearly a $50 \%$ increase in the peak value of the total droplet concentration in simulation STICK $=0.035$ compared to the base case. Condensational growth is inhibited in comparison to the base case, thereby limiting the rate at which small droplets grow large enough to be readily removed through collisions with larger drops. The drizzle flux is only slightly reduced (the greatest reduction, at cloud top, is $<5 \%$ ). Liquid water is increased at all altitudes above $400 \mathrm{~m}$; there is a $10 \%$ increase in the maximum liquid water at cloud top. Decreased $r_{\text {eff }}$ and increased $q_{1}$ contribute to a $13 \%$ increase in both optical depth and the peak longwave cooling, and a $5 \%$ relative increase in albedo.

We conclude that the value of the condensation coefficient has a noticeable effect on cloud microstructure in our model. These effects are likely overestimated due to horizontal averaging, because droplets in the model are probably subjected to artiticially long periods of time in saturated conditions near cloud top ( see section $3 \mathrm{c}$ ).

\section{f. Surface flux-profile relationships}

In our evaluation of surface fluxes we employ the dimensionless profiles of momentum and heat in the surface layer measured by Dyer (1974). An alternate set of profiles given by Businger et al. ( 1971 ) was used by Duynkerke and Driedonks (1987). Besides suggesting slightly different dimensionless profiles, Businger et al. (1971) also recommend a different value for von Kármán's constant $(0.35$, rather than 0.40 , as usually assumed ); furthermore, they concluded that the ratio of the eddy diffusivities for heat and momentum is $>1$. To investigate the sensitivity of our model results to these differences, we ran a simulation (FLUX_PROFILES) that employs the dimensionless profiles of Businger et al., uses their recommended value of von Kármán's constant, and assumes a ratio of eddy diffusivity between heat (vapor also) and momentum of 1.35 at all altitudes $\left(\sigma_{h}^{-1}=1.35\right)$.

Due to the smaller value of von Kármán's constant, the surface shear production of $E$ at $12 \mathrm{~h}$ is reduced by $\sim 30 \%$ in simulation FLUX_PROFILES, resulting in decreased $E$ in the subcloud layer. But most of the differences between this simulation and our base case are due to the increased ratio between eddy diffusivities of momentum and vapor. The increased eddy diffusivities result in a greater flux convergence of $q_{\mathrm{v}}$ in the upper region of the cloud layer, leading to increased supersaturation in this region (Table 2 ). The higher supersaturation nucleates more droplets and increases $q_{1}$ 
above $600-\mathrm{m}$ altitude, resulting in an enhancement of peak longwave cooling. In contrast to the other model simulations discussed above, where an increase in droplet concentration lowers drizzle fluxes and increases $q_{1}$, in this case an increase in $q_{1}$ leads to higher drizzle fluxes in the top $200 \mathrm{~m}$ of the cloud layer. Below $600 \mathrm{~m}$, where the flux divergence of $q_{\mathrm{v}}$ is greater than in the base case, the supersaturation is lowered, reducing $q_{1}$ and the concentration of droplets. These compensating effects result in essentially no change in liquid water path, optical depth, and albedo.

We conclude that although the choice of surface flux profiles and eddy diffusivity ratios can affect mixing and cloud microstructure, cloud optical properties are not very sensitive to the values assumed for these parameters.

\section{g. Probability distribution function for saturation}

Calculation of the buoyancy flux requires an evaluation of the fraction of air that is saturated at the boundaries between grid layers (see appendix $\mathrm{C}$ ). The fractional saturation is computed by integrating over all the saturated states in a semi-conservative thermodynamic phase space, which requires an assumed form of the distribution of states in the phase space. In our base case simulation, an exponential probability distribution function (PDF) is assumed. To explore the sensitivity of the model to the form of this function, we have run another simulation (PDF_HEAVISIDE), in which the PDF is represented by the Heaviside function. Instead of a continuous distribution of states, this step function describes a situation in which the air is either entirely saturated or entirely below saturation. This "all or nothing" condensation scheme is equivalent to that used by Duynkerke and Driedonks ( 1987) and Duynkerke (1988).

The greatest impact of changing the PDF is greater decoupling between the cloud and subcloud layers. Interestingly, N84 describes the turbulent structure of the atmospheric boundary layer during the period of observations as decoupled. In comparison to our base case, in simulation PDF_HEAVISIDE $q_{\mathrm{v}}$ is increased below 300-m altitude and slightly diminished above. Above $300 \mathrm{~m}, T$ is reduced by $\sim 0.1 \mathrm{~K}$, and $q_{1}$ is slightly increased (Table 2). Because the buoyancy flux is increased in the lower regions of the cloud (where the fraction of condensed states in the base case is $<1$ ), $E$ is increased there in simulation PDF_HEAVISIDE. Below the supersaturated region of the main cloud layer (near 350-m altitude in this case), the fraction of condensed states in this simulation plummets to zero, resulting in a drastic minimum in turbulent fluxes that leads to a more pronounced minimum in $E$ in this region. Because vertical mixing between the main cloud and the subcloud layers is thereby limited, $q_{\mathrm{v}}$ climbs enough in the subcloud layer to saturate one model layer in this simulation, at $300-\mathrm{m}$ altitude. This feature could be interpreted to represent the cumulus clouds that N84 observed to rise into the thinning stratocumulus layer later in the afternoon.

We conclude that the form of the probability distribution function used in the partial condensation scheme can have a noticeable effect on the vertical structure of the boundary layer.

\section{h. Treatment of horizontal divergence within the model domain}

Many models of the atmospheric boundary layer solve the dynamic equations in advective form and do not solve the continuity equation for air density (e.g., Bougeault 1985; Duynkerke and Driedonks 1987; Chen and Cotton 1987). When the vertical wind converges, air must either accumulate or "leak" out of the sides of the grid layers. When the $1 \mathrm{D}$ dynamic equations are solved in advective form, mass continuity is ignored, thereby implicitly leaking air from the sides to compensate for vertical mass convergence. Because the dynamic equations are solved in flux form in our model, in the base case air is explicitly leaked out of the sides, thereby keeping a constant air mass column in the model domain [ the second term in Eqs. (1), (2), (10), (11), and (13)]. In a further simulation (PRESSURE_RISE), we investigated the effect of allowing the air mass in a column to accumulate in the model domain by omitting this second term. For this sensitivity test, pressure was recalculated at all levels after each time step. The pressure at the top of the model was fixed at its initial value, which implies that horizontal convergence above the model domain maintained the mass of the air column. Instead of balancing the fluxes of particles, vapor, and potential temperature out of the bottom of the highest model layer, advective fluxes into the top of the model were calculated by assuming constant vertical gradients of concentrations.

In $12 \mathrm{~h}$ of the PRESSURE_RISE simulation, the surface pressure increased by $14 \mathrm{mb}$. Such a rate of pressure increase cannot be sustained for much longer than a day before the surface pressures become unrealistic (the leaking and accumulating treatments could be combined to offset this problem over longer simulations ). The changes in pressure and density raise the top of the model by $107 \mathrm{~m}$ from its initial altitude of $1 \mathrm{~km}$. The increase in pressure does not affect $\theta$ ( at constant sigma levels) but it does increase $T$. Because $q_{v}$ is not affected by the increase in pressure, the relative humidity decreases. The reduced relative humidity decreases cloud depth (Table 2) and evaporates the drizzle before it reaches the surface. The liquid water path is reduced significantly, leading to reductions in optical depth and the peak longwave cooling rate. The resulting decrease in albedo is small.

We conclude that the method of treatment of horizontal divergence modestly affects our model results, and it has a pronounced effect on drizzle reaching the surface. 
TABLE 3. Variations in input CN size distributions. The volume-weighted mean radius $\left(r_{v}\right)$ is determined by $r_{\text {॥ }}$ and $\sigma$

\begin{tabular}{|c|c|c|c|c|c|}
\hline Model simulation & $\begin{array}{c}r_{n} \\
(\mu \mathrm{m})\end{array}$ & $\sigma$ & $\begin{array}{c}r_{v} \\
(\mu \mathrm{m})\end{array}$ & $\begin{array}{c}\text { Initial } \\
\text { concentration } \\
\left(\mathrm{cm}^{3}\right)\end{array}$ & $\begin{array}{l}\text { Production } \\
\text { rate } \\
\left(\mathrm{cm}^{3} \mathrm{~s}^{\prime}\right)\end{array}$ \\
\hline BASE_CASE & 0.05 & 2.5 & 0.62 & 1000 & 0.018 \\
\hline CN_SIG2_R.05 & 0.015 & 20 & 0.21 & $160(10)$ & 0.028 \\
\hline CN_SIG2_R.15 & 0.15 & 2.0 & 0.63 & $3(10)$ & 0.00 .3 \\
\hline CN_SIGI.2_R.I2 & 0.12 & 1.2 & 0.13 & 500 & $0.0 \times 15$ \\
\hline CN_SIG1.2_R.56 & 0.56 & 1.2 & 0.62 & 120 & 0.00 .35 \\
\hline
\end{tabular}

\section{Sensitivity of model to environmental parameters}

The environmental parameters measured by $\mathrm{N} 84$ are nearly sufficient to specify all of the boundary conditions required to run our base case model simulation ( section $3 \mathrm{a}$ ). However, the values of a few parameters had to be assumed. Notable among these is the characterization of the $\mathrm{CCN}$ in the atmosphere during the period of observations. Also, the divergence rate of the horizontal wind velocity, the sea surface temperature, and the history of the air mass were not reported by N84. There is also uncertainty in the downwelling flux of longwave radiation. In this section we investigate the sensitivity of the model results to the assumed values of these environmental parameters.

\section{a. Characterization of $\mathrm{CCN}$}

Nicholls (1984) did not measure droplets $<1 \mu \mathrm{m}$ in radius, therefore nothing is known about the $\mathrm{CCN}$ upon which the observed cloud droplets formed. As described above, for the input $\mathrm{CN}$ distribution in our base case simulation we matched the shape of $\mathrm{CCN}$ activation spectra measured underneath stratus clouds off the California coast and adjusted the total number and production rate to approximately match the average total droplet concentration measured by N84. To examine the effects of variations in the input $\mathrm{CN}$ distribution on the model results, we ran five further simulations: one to evaluate the role of sea salt particles, two to address the sensitivity of the results to small variations in the slope of the CCN spectrum, and two to investigate the effects of nearly monodisperse input $\mathrm{CN}$ distributions. Some caution is warranted in interpreting the significance of the results of these sensitivity tests, given the importance of supersaturations on droplet nucleation and the likely shortcomings of the horizontally averaged supersaturation field predicted by the model.

Because the spectral width of the $\mathrm{CN}$ distribution used in our base case simulation is so broad $(\sigma=2.5)$, it represents not only the small sulfate particles $(r<1$ $\mu \mathrm{m})$ that dominate the number concentration of particles in the marine atmosphere but also the "giant" nuclei $(r>1 \mu \mathrm{m})$ consisting of sea salt particles. This was verified by comparing our $\mathrm{CN}$ distributions with sea salt measurements by Woodcock (1953) taken at wind speeds corresponding to those observed by $\mathrm{N} 84$.
Due to interest in possible effects of giant nuclei on precipitation (e.g., Beard and Ochs 1993), we evaluated their role under the conditions observed by N84 by running a model simulation (NO_SEA_SALT) in which there were no input $\mathrm{CN}$ with radius $>1 \mu \mathrm{m}$. In our base case simulation there are initially $1 \mathrm{~cm}^{3}$ of $\mathrm{CN}$ with radii $>1 \mu \mathrm{m}$ (out of 1000 ) total), and giant nuclei compose $35 \%$ of the total mass.

The effects of eliminating the source of giant nuclei are modest (Table 2 ). The number of droplets $<5 \mu \mathrm{m}$ in radius increases, leading to an increase in the total concentration of droplets $\left(N_{\text {drops }}\right)$. Although the peak supersaturation at cloud top is the same as in the base case, supersaturation below cloud top is slightly increased in the NO_SEA_SALT simulation. This increase in supersaturation leads to a slight increase in $r_{\mathrm{ctf}}$ that gives rise to an increased drizzle flux. The resulting relationship is a counter example to the conventional wisdom that increased $N_{\text {srrops }}$ leads to decreased drizzle fluxes (Albrecht 1989; Baker and Charlson 1990). The difference between our results in this case and conventional wisdom is because in our model the increase in droplet concentration is limited to droplets that are so small that they have little effect on the cloud microphysics. We conclude that under conditions of relatively high droplet concentrations, giant nuclei play a minor role in the microphysics of our model.

The input $\mathrm{CN}$ distributions for the four remaining $\mathrm{CN}$ sensitivity tests are given in Table 3 . In simulations CN_SIG2_R.05 and CN_SIG2_R.15, the geometric standard deviation of the $\mathrm{CN}$ distribution $(\sigma)$ is reduced from 2.5 to 2 ; in simulation CN_SIG2_R.05, $r_{\mathrm{n}}$ is unchanged from the base case, while in simulation CN_SIG2_R.15, the geometric mean volume radius $\left(r_{v}\right)$ is unchanged. The initial number and production rate of $\mathrm{CN}$ were chosen to produce a below-cloud $\mathrm{CCN}$ activation spectra at $12 \mathrm{~h}$ that intersects that of the base case at its peak supersaturation of $\sim 0.04 \%$ ( seen in Fig. 11 ), since such a constraint could be expected to result in similar $N_{\mathrm{drops}}$. The issue of interest in these two simulations is to see whether or not small changes in the slope of the $\mathrm{CCN}$ activation spectrum affect the model results.

The activation spectrum (for supersaturation between 0.01 and $0.1 \%$ ) in simulation CN_SIG2_R.05 
is steeper than that for the base case (Fig. 11). The increased slope results in increased supersaturation at all altitudes within the cloud layer, which produces higher $N_{\text {drops }}$ above $600-\mathrm{m}$ altitude. However, the higher supersaturations also produce an increase in $r_{\mathrm{eff}}$. Bigger droplets produce greater drizzle fluxes than in the base case, as well as reductions in optical depth, peak longwave cooling, and albedo. This simulation is another counter example to the conventional wisdom that increased $N_{\text {drops }}$ leads to reduced drizzle fluxes.

In contrast to the previous simulation, in simulation CN_SIG2_R.15 the activation spectrum for supersaturations between 0.01 and $0.1 \%$ is less steep than for the base case (Fig. 11). The decreased slope results in lower supersaturations, and $N_{\text {drops }}$ is increased at all altitudes. The increase in $N_{\text {drups }}$ results in slightly reduced $r_{\text {eff }}$ in the upper region of the cloud layer. Although the drizzle fluxes are changed only slightly, the cloud layer is deeper than in the base case, giving rise to increased cloud water. The increased $q_{1}$ leads to a greater optical depth and albedo. We conclude that the small variations in the distribution of $\mathrm{CN}$ have a modest effect on our model results.

The input size distributions for simulations CN_SIG1.2_R.12 and CN_SIG1.2_R.56 are nearly monodisperse ( $\sigma=1.2$ ). The particle size distribution in CN_SIG1.2_R.12 is similar to surface measurements of sulfate over the remote, cloud-free Pacific Ocean (Clarke et al. 1987). The size distribution of $\mathrm{CN}$ in CN_SIG1.2_R.56 represents oversimplification of the nucleation process in that either all or none of the $\mathrm{CN}$ are activated. The peak supersaturation from the base case $(\sim 0.04 \%)$ corresponds to the maximum slope in the activation spectrum of CN_SIG1.2_R.12 (Fig. 11), while all of the $\mathrm{CN}$ are activated at that supersaturation for the distribution in CN_SIG1.2_R.56.

In simulation CN_SIG1.2_R.12, the supersaturation is increased at all levels in the cloud layer, but nucleation is limited to cloud top, and $N_{\text {drups }}$ is increased only in the upper half of the cloud layer. At cloud top the dramatic increase in $N_{\text {drops }}$ is caused by a new peak in the size distribution for droplet radius between 2 and 3 $\mu \mathrm{m}$. But these droplets are so small that their impact on cloud microphysics is overwhelmed by the effect on condensational growth of increased supersaturations throughout the cloud layer. This enhanced condensational growth produces increased $r_{\mathrm{etf}}$ and drizzle fluxes. Increased drizzle decreases $q_{1}$, this, in combination with increased $r_{\text {eff }}$, results in a $15 \%$ decrease in optical depth and a relative decrease in albedo of $13 \%$. This simulation serves as yet another counter example to the expected effects of increased $N_{\text {drops }}$ on drizzle, $q_{1}$, and albedo.

In simulation CN_SIGI.2_R.56, the peak of supersaturation is drastically reduced (by a factor of three) from that in the base case, but, because the $\mathrm{CN}$ are activated at such a low supersaturation (below $0.01 \%$ ), $N_{\text {drops }}$ is enhanced over that in the base case. In this

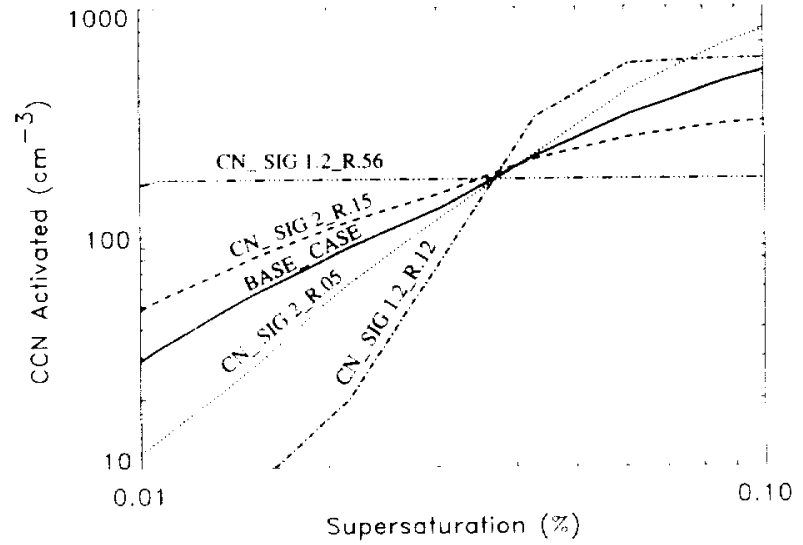

FIG. 11. Comparison of modeled cumulative $\mathrm{CCN}$ activation spectra at $12 \mathrm{~h}$ and $150-\mathrm{m}$ altitude for base case (solid), CN_SIG2_R.05 (dotted). CN_SIG2_R.15 (dashed). CN_SIG1.2_R.12 (dot-dashed), and $C N$ SIGI 2 R 56 is tri-dot-dashed.

simulation the increase in $N_{\text {drups }}$ results in a decreased $r_{\text {eff }}$, which leads to decreased drizzle fluxes, resulting in increased peak $q_{1}$. Smaller droplets and increased $q_{1}$ reinforce an increase in optical depth and albedo. The increase in optical depth leads to an increased peak longwave cooling, which results in a deeper cloud that entrains more inversion air. We conclude that treating the marine aerosol as nearly monodisperse has a significant impact on the model results.

\section{b. Downwelling longwave radiation}

As is typical of marine stratocumulus, in the observations reported by $\mathrm{N} 84$, as well as in our model simulations, the buoyancy flux provided by cloud-top radiative cooling drives most of the vertical mixing in the boundary layer. Cloud-top radiative cooling depends on the downward flux of longwave radiation, which is specified in our base case simulation (at $270 \mathrm{~W} \mathrm{~m}^{-2}$ ) to match the radiative calculations presented in N84. N84 also measured the downwelling longwave radiative flux, which had an average value $15 \mathrm{~W} \mathrm{~m}^{-2}$ greater than their calculations. In their study of five further cases of stratocumulus over the North Sea, Nicholls and Leighton (1986) found a similar error of comparable magnitude in all of their comparisons of radiative calculations and measurements for downwelling radiative flux above cloud top. which they ascribed to a systematic measurement error. Because this flux is so important to the cloud-top radiative cooling rate, we ran a model simulation ( $L W_{-}$FLUX) in which the downwelling flux at $900-\mathrm{m}$ altitude was the same as that measured in N84 (at $285 \mathrm{~W} \mathrm{~m}^{2}$ ). This increase in the downwelling flux above cloud top was produced by increasing the temperature of the blackbody radiative source at the top of layer 0 .

After $12 \mathrm{~h}$ of this simulation, the peak longwave cooling rate is $22 \%$ less than in the base case, which 
reduces vertical mixing. The in-cloud peak of $E$ is reduced by $20 \%$ from the base case, and the inversion height increases by only $10 \mathrm{~m}$ in $12 \mathrm{~h}$. Less mixing and less cooling produce a $14 \%$ decrease in the peak supersaturation, though the peak in $q_{1}$ is only slightly reduced. Because of reduced mixing, the drizzle fluxes are diminished at all altitudes. The changes in mixing and drizzle bring the model results in closer agreement to the observations. We conclude that a $15 \mathrm{~W} \mathrm{~m}^{-2}$ increase in the downwelling longwave radiative flux has an appreciable effect on cloud dynamics, but the effect on optical properties is modest.

Chen and Cotton ( 1987 ) performed a similar sensitivity test of their model results to the downwelling longwave radiative flux by prescribing an upper-level cloud deck above the boundary layer ( their experiment $\mathrm{HICl}$ ). The increase in downwelling longwave radiation in their sensitivity test was greater than in ours (it reduced their peak longwave cooling rate by $>50 \%$ ), and resulted in a greater decrease in the peak value of $q_{1}$ (it fell by nearly $30 \%$ in their test).

\section{c. Divergence rate of horizontal wind velocity}

Because the large-scale divergence rate of horizontal wind velocity (div) represents a small difference between large terms, it is difficult to measure reliably. In the observations of $\mathrm{N} 84$ it was not reported. In our base case simulation we use a value of $2.5 \times 10^{-6} \mathrm{~s}^{-1}$. By causing subsidence of ( warm and dry) inversion air, it affects the dynamics of boundary layer mixing by offsetting cloud-top longwave cooling. To investigate the effects of variations in the divergence rate, we have run two further simulations: DIV0, in which no divergence is imposed, and DIV $\times 2$, in which div is doubled from the value used in the base case.

In the base case simulation, subsidence produces 3.1 $\mathrm{K} \mathrm{h}{ }^{-1}$ of heating at cloud top at $12 \mathrm{~h}$, which is more than one-third the longwave cooling rate (Table 2 ). In DIV0 this subsidence heating no longer operates, which allows the inversion height to increase by twice that in the base case and results in a cloud layer over $100 \mathrm{~m}$ deeper. Although the cloud layer is deeper, increased drizzle at all altitudes prevents any increase in the peak value of $q_{1}$. But the increased cloud depth does increase the liquid water path, resulting in a $11 \%$ increase in optical depth and a relative increase in albedo of $4 \%$.

Doubling the divergence rate to $5 \times 10^{-6} \mathrm{~s}^{-1}$ in simulation DIV $\times 2$ leads to a more sharply defined inversion at $12 \mathrm{~h}$, in which the increased subsidence produces $7.2 \mathrm{~K} \mathrm{~h}^{-1}$ of heating at cloud top. This heating nearly offsets the cloud-top longwave cooling, although the latter extends down a few more layers. where it is not offset by subsidence. Less net cloud-top cooling results in a cloud layer that is $80 \mathrm{~m}$ shallower than in the base case. Instead of the inversion height increasing, it decreases by $20 \mathrm{~m}$ below its initial value in simulation DIV $\times 2$. With less net cloud-top cooling, the peak supersaturation is reduced; this, in combination with the shallower cloud layer, reduces the peak $q_{1}$ by $12 \%$. The total concentration of droplets increases because drizzle rates are significantly reduced at all altitudes. The net of these changes is to produce a $15 \%$ reduction in optical depth and a relative albedo reduction of $5 \%$. We conclude that variations in the divergence rate can cause significant variations in cloud properties.

Chen and Cotton ( 1987 ) found a similar sensitivity of their model results to the divergence rate of horizontal wind velocity. In their simulations of a shallower, shear-driven stratocumulus-topped marine boundary layer, they found that the peak value of $q_{1}$ decreased in response to an increased divergence rate.

\section{d. Sea surface temperature and airmass history}

Because sea surface temperatures (SST) were not reported by $\mathrm{N} 84$, for the base case simulation we used the climatological average July value for the measurement area. To investigate the sensitivity of our model results to a small difference in SST, we ran a further simulation in which SST was increased by $1 \mathrm{~K}$. Another unknown in comparing our model results with the N84 observations is the history of the air mass. Although the measurements presented in N84 characterized the state of the boundary layer over a period of $\sim 4 \mathrm{~h}$, they were still only a snapshot in time. To crudely represent an alternative history of the air mass from that represented by our base case simulation, we ran a further simulation in which the initial temperatures throughout the boundary layer were increased by $1 \mathrm{~K}$. This alternative history is logistically designed to bring the predicted boundary layer temperatures closer to the observations; it is physically justifiable because the air mass may have been influenced by passing over Scotland before it reached the North Sea.

In simulation SST +1 the SST is increased by $1 \mathrm{~K}$. After $12 \mathrm{~h}, \mathrm{SST}+1$ results in a surface buoyancy flux of $19 \mathrm{~W} \mathrm{~m}^{-2}$, compared to $14 \mathrm{~W} \mathrm{~m}^{-2}$ in the base case. The enhanced surface buoyancy produces turbulent fluxes near the surface that are in the upper range of the observed fluxes. In contrast, the fluxes near the surface in the base case split the differences between the observed values (Fig. 8). The increased surface source of heat (both sensible and latent) produces a boundary layer at $12 \mathrm{~h}$ that was $\sim 0.5 \mathrm{~K}$ warmer than in the base case; this matches the temperature and vapor measurements more closely, but is still colder ( by $\sim 0.5 \mathrm{~K}$ ) than the measurements in the cloud layer. In contrast, $\mathrm{SST}+1$ produces an upwelling longwave radiative flux near the surface that is further from the radiative calculations of N84 than our base case simulation, in which the values are already slightly higher than N84 calculated (Fig. 6). Other changes from the base case include a $10 \%$ increase in the peak value of the tur- 
bulent kinetic energy in cloud, an inversion height increase $20 \mathrm{~m}$ greater than in the base case, and slightly increased drizzle fluxes. Although Table 2 indicates that the peak longwave cooling rate is $22 \%$ less than the base case, this is a transient effect due to the entrainment of a new layer just before the output at $12 \mathrm{~h}$; it does not represent a sustained difference from the base case.

In testing the sensitivity of their model results to an increased SST (which they increased by $7 \mathrm{~K}$, in contrast to our increase of $1 \mathrm{~K}$ ), Chen and Cotton (1987) also found that entrainment of inversion air was enhanced. However, in contrast to our results, they found that the peak value of $q_{1}$ was reduced, and the cloud base descended, when the SST was increased (in our results neither changed in response to the smaller increase in SST).

In simulation BLT +1 , the initial temperatures in the boundary layer are increased by $1 \mathrm{~K}$, but the SST is the same as the base case. This reduces the surface boundary flux to $9 \mathrm{~W} \mathrm{~m}^{-2}$ at $12 \mathrm{~h}$ (compared to $14 \mathrm{~W} \mathrm{~m}^{-2}$ in the base case). The boundary layer temperatures at $12 \mathrm{~h}$ in simulation BLT +1 are $\sim 0.1 \mathrm{~K}$ higher than in simulation SST +1 . Although there is a slight increase in the droplet concentration, as in simulation SST +1 , the changes in cloud optical properties are negligible. We conclude that small variations in SST and initial air temperature in the boundary layer produce small changes in the model results.

\section{Summary}

In this paper we have described a ID model for the stratocumulus-topped marine boundary layer, which includes aerosol and cloud microphysics, radiative transfer, and vertical mixing. We have compared the outputs of the model with measurements and have tested the sensitivity of the model to physical assumptions and environmental uncertainties.

Although the model includes a detailed treatment of aerosol and cloud microphysics and radiative transfer, the representation of air motions is highly simplified. The most significant shortcoming of $1 \mathrm{D}$ models such as this is that grid layers represent averages over updrafts and downdrafts. In the upper region of the cloud this model simplification probably results in droplets being exposed to supersaturated conditions for artificially long time periods. In the lower region of the modeled cloud, on the other hand, there is probably excessive evaporation of cloud droplets, which likely results in overprediction of mixing between the cloud and the subcloud layers. Another likely consequence of averaging over updrafts and downdrafts is that peak supersaturations are underpredicted by the model. Therefore, the model likely underpredicts the number of $\mathrm{CN}$ that serve as $\mathrm{CCN}$.

With these caveats in mind, the following results have been obtained from the model simulations described in this paper.
- The model predictions of thermodynamics, microphysical properties, and radiative fluxes are generally in reasonable agreement with measurements in an $\sim 500$-m thick, summertime marine stratocumulus cloud layer. However, the model predictions of turbulent fluxes between the cloud and subcloud layers exceed the measurements.

- The variations in cloud properties between thick stratus measured under gale conditions and high, thin stratocumulus layer are generally reproduced by the model, although it underpredicts the entrainment of overlying air at cloud top under gale conditions. Although the drizzle fluxes predicted by the model are within the measurement uncertainties, the maxima are consistently overpredicted.

- Most observations of stratiform clouds show that the total concentration of cloud drops $\left(N_{\text {drops }}\right)$ is not strongly dependent on height. However, the modeled profile of $N_{\text {drom }}$ is not necessarily constant with height in the cloud layer. Changes in $N_{\text {drops }}$ with height are sensitive to the lower droplet size cutoff and the population of large unactivated haze particles. For a lower droplet size cutoff of $2.2 \mu \mathrm{m}$, the profile of droplet concentration correlates with the supersaturation profile in the cloud layer. Particles with radius $\sim 1 \mu \mathrm{m}$ can contribute to $N_{\mathrm{drops}}$, but because they are so small they have little effect on the microphysics of the cloud layer.

- While it is often the case that increases in $N_{\text {drops }}$ lead to decreased drizzle fluxes, and therefore increases in cloud water, this is not always the case in our model simulations. This is because in our model increased concentrations of small droplets $(r<5 \mu \mathrm{m})$ can enhance $N_{\text {drups }}$ while having little effect on cloud microphysical processes. When this happens, the radius of the mean droplet volume $\left(\tilde{r}_{\mathrm{V}}\right)$ is no longer a useful indicator of average droplet size (i.e., increased $\tilde{r}_{\mathrm{V}}$ is not associated with increased drizzle fluxes), because it is so sensitive to the concentrations of small droplets. The area-weighted droplet radius $\left(r_{\mathrm{eff}}\right)$ is a more meaningful indicator of the average size of cloud droplets because, in our model simulations, it was always positively correlated with the drizzle flux.

- The effect of radiative transfer on droplet condensational growth leads to significant changes in the structure of the modeled cloud layer. Droplet radiative cooling leads to a lower supersaturation and less droplet nucleation near cloud top. This effect is generally ignored in cloud models; our model results suggest that it may be important when cloud-top radiative cooling is significant. We recommend that this effect be explored further with other models.

- Infrared scattering, which is also generally ignored in cloud models, has noticeable effects on the structure of the modeled cloud layer. Cloud-top radiative cooling decreases when infrared scattering is included in the model. 
- A factor of 2 change in the collision efficiencies between droplets with radii $<30 \mu \mathrm{m}$ has a noticeable effect on the properties of the modeled cloud layer.

- The value of the condensation coefficient for droplet growth has a noticeable effect on the properties of the modeled cloud layer; a smaller value produces smaller droplets and increased cloud water.

- Small differences in the characterization of the input particle distributions influence the model results only slightly. However, the assumption of a nearly monodisperse $\mathrm{CN}$ distribution dramatically alters the properties of the modeled cloud layer.

- The divergence rate of the horizontal wind velocity has a noticeable effect on the modeled cloud structure.

Acknowledgments. We thank E. J. Jensen for modifying the coagulation routines to treat the second moments of the dissolved CCN distributions, and D. A. Hegg and C. S. Bretherton for useful discussions. We also thank $S$. Krueger and two anonymous reviewers for their constructive suggestions. This research was supported by grants from NASA, DOE, and NSF (ATM-9015189). Computations were performed at the Numerical Aerodynamic Simulation Program facility at Ames.

\section{APPENDIX A}

\section{Symbols}

$A_{\mathrm{k}}, A_{\mathrm{s}} \quad$ Kelvin and solute factors in the condensational growth kernel

$A_{\mathrm{v}} \quad$ Avogadro's number

$B \quad$ mean radiative intensity

$c_{\mathrm{d}}, c_{\mathrm{h}} \quad$ surface drag and heat transfer coefficients

$c_{\mathrm{p}} \quad$ specific heat at constant pressure of dry air

$C$ concentration of droplets in a size bin

$c_{\mu}, c_{1}, c_{2}$ constants in turbulence model [values given in Duynkerke (1988)]

$D$

div

$E \quad$ turbulent kinetic energy

$f \quad$ Coriolis parameter

$F_{\mathrm{v}}, F_{\mathrm{t}} \quad$ vapor and thermal ventilation factors

$g \quad$ gravitational acceleration

$G \quad$ water vapor concentration

$g_{\mathrm{r}} \quad$ droplet condensational growth rate

$J$ Planck function

$K_{\mathrm{m}} \quad$ gradient diffusion coefficient for momen-

tum

$k \quad$ von Kármán's constant

$k_{\mathrm{abs}} \quad$ radiative absorption coefficient for a particle size bin

$K_{\mathrm{B}}, K_{\mathrm{c}} \quad$ thermal (Brownian) and total coagulation kernels

$K_{1} \quad$ thermal conductivity of air

$L \quad$ Monin-Obukhov length

$L_{\mathrm{v}} \quad$ latent heat of water vaporization
$M \quad$ mean wind speed

$m_{s}, m_{\mathrm{w}} \quad$ masses of solute and water, respectively, in a droplet

$M_{s}, M_{\mathrm{w}} \quad$ molecular weights of solute and water

$n_{\text {s. }}$

$N_{\text {drop. }}$

$n_{\text {vap }}$

$P$

$q_{\text {rad }}$

q.

$q$

$q_{1}, q_{v}$

$r, r$

$R$

$r_{\text {crit }}$

$\tilde{r}_{\mathrm{v}}$

$r_{\mathrm{eff}}$

$r_{n}, r_{v}$

$R_{\mathrm{n}}$

$S$

$S_{\text {rrit,KK }}, S_{\text {trit }}$

ambient vapor pressure

total droplet concentration

saturation vapor pressure of liquid water

production rate of $E$

droplet radiative heating rate

saturation vapor mixing ratio

total water mixing ratio

liquid and water vapor mixing ratios

particle radii

universal gas constant

critical radius for droplet activation

radius of mean droplet volume

effective (arca-weighted) droplet radius

geometric mean number and mean vol-

ume radii, respectively, of lognormal

$\mathrm{CN}$ distribution

particle loss rate

water vapor supersaturation

critical supersaturations for droplet acti-

vation, ignoring and including radiative effect

$S_{\mathrm{n}} \quad$ source of particles

$T, T_{0}$ time-dependent and initial air temperatures

$t$ time

$u, v$

$u_{*}$

$u_{\mathrm{g}}, v_{\mathrm{g}}$

$v_{\text {dep.p }}, v_{\text {dep. }}$

horizontal wind components

surface wind stress

components of geostrophic wind

deposition velocities for particles and water vapor

$v_{\text {dep. }}$,

$v_{\mathrm{f}}$

$w$

$w_{*}$

$z$

$z_{0}$

$z_{1}$

$z_{h}$

$e^{2}$

$\epsilon$

$\phi_{\mathrm{m}}, \phi_{\mathrm{h}}$

surface transfer velocity for sensible heat

particle fall speed

vertical wind speed

convective velocity scale

altitude above ocean surface

surface aerodynamic roughness height

altitude at which surface values of $E$ and $\epsilon$ are evaluated $(1.5 \mathrm{~m})$

altitude at which stress falls to $5 \%$ of its surface value

dissipation rate of $E$

dimensionless gradients of momentum and potential temperature

$\Phi_{\text {s }} \quad$ practical osmotic coefficient of dissolved CCN

$\nu, \lambda \quad$ radiative frequency and wavelength

$\nu_{\mathrm{d}} \quad$ dissociativity of dissolved $\mathrm{CCN}$

$\theta \quad$ potential temperature

$\theta_{\mathrm{e}} \quad$ equivalent potential temperature $\mathrm{I}=\theta+$ $\left.\left(L_{1} \theta / c_{\mathrm{p}} T\right) q_{\mathrm{n}}\right]$

$\theta_{1} \quad$ liquid potential temperature $\left[=\theta-\left(L_{v} \theta\right)\right.$ $\left.\left.c_{\mathrm{p}} T\right) q_{1}\right]$

$\theta_{v}, \theta_{v 0} \quad$ time-dependent and initial virtual potential temperatures 


$\begin{array}{ll}\rho, \rho_{\mathrm{w}} & \begin{array}{l}\text { densities of air and liquid water } \\ \text { geometric standard deviation of lognor- } \\ \text { mal CN distribution } \\ \sigma_{\mathrm{p}}, \sigma_{\mathrm{h}}\end{array} \\ \begin{array}{l}\text { turbulent Prandt numbers for particles } \\ \text { and heat } \\ \sigma_{\mathrm{E}}, \sigma_{\mathrm{t}}\end{array} & \begin{array}{l}\text { turbulent Prandtl numbers for } E \text { and } \epsilon \\ \text { [ values given in Duynkerke ( 1988)] } \\ \sigma_{\mathrm{w}}\end{array} \\ \psi_{\mathrm{m}}, \psi_{\mathrm{h}} & \begin{array}{l}\text { surface tension of water } \\ \text { integrated dimensionless profiles of mo- } \\ \text { mentum and temperature }\end{array}\end{array}$

APPENDIX B

\section{Buoyancy Flux}

The buoyancy flux is an important term in the $E$ equation for the stratocumulus-topped marine boundary layer. Because $\theta_{v}$ is not conserved under saturated conditions, gradient transfer is only appropriate under unsaturated conditions. Here we describe how the saturated and unsaturated fluxes are combined.

Applying a Reynolds average to the definition of $\theta_{\mathrm{s}}$ yields its turbulent flux:

$$
\begin{aligned}
\overline{w^{\prime} \theta_{v}^{\prime}}=\left(1+0.61 q_{v}\right. & \left.-q_{1}\right) \overline{w^{\prime} \theta^{\prime}} \\
& +0.61 \theta \overline{w^{\prime} q_{v}^{\prime}}-\theta \overline{w^{\prime} q_{1}^{\prime}} .
\end{aligned}
$$

Under saturated conditions, the Clausius-Clapeyron relation and the Boussinesq approximation lead to

$\left.\overline{w^{\prime} q_{y}^{\prime}}\right)_{\text {sat }}=\alpha \overline{w^{\prime} \theta^{\prime}}, \quad$ where $\quad \alpha=\frac{T}{\theta} \frac{\mathrm{d} q_{\mathrm{s}}}{\mathrm{d} T}=\frac{L_{\mathrm{v}} q_{\mathrm{s}}}{R_{\mathrm{v}} T \theta}$,

and $q_{\mathrm{s}}$ is the saturation specific humidity. Applying a Reynolds average to a linearized form of $\theta_{\mathrm{e}}$ :

$$
\overline{w^{\prime} \theta^{\prime}}=\overline{w^{\prime} \theta_{\mathrm{e}}^{\prime}}-\frac{\theta L_{\mathrm{v}}}{T c_{\mathrm{p}}} \overline{w^{\prime} q_{\mathrm{v}}^{\prime}} .
$$

Equations (B2) and (B3) yield

$$
\left.\overline{w^{\prime} q_{\mathrm{v}}^{\prime}}\right)_{\mathrm{sat}}=\frac{\alpha}{\beta} \overline{w^{\prime} \theta_{\mathrm{e}}^{\prime}}, \quad \text { where } \quad \beta=1+\frac{\theta L_{\mathrm{v}}}{T_{c_{\mathrm{p}}}} \alpha .
$$

Substituting Eq. (B4) back into Eq. (B3) yields

$$
\left.\overline{w^{\prime} \theta^{\prime}}\right)_{\text {sat }}=\overline{w^{\prime} \theta_{\mathrm{e}}^{\prime}} / \beta \text {. }
$$

Finally, the turbulent flux of $q_{1}$ is just the difference between the turbulent fluxes of total water $\left(q_{\mathrm{t}}\right)$ and $q_{\mathrm{v}}$. The saturated buoyancy flux is evaluated through Eqs. (B3) - (B5), in which the turbulent fluxes of the semiconservative variables $\theta_{\mathrm{c}}$ and $q_{1}$ are evaluated through gradient transfer, while the unsaturated buoyancy flux uses gradient transfer directly.

The unsaturated and saturated buoyancy fluxes are combined through a weighting factor, $\boldsymbol{R}_{s}$, which represents the fraction of saturated air at a given level:

$$
\left.\left.\overline{w^{\prime} \theta_{\mathrm{v}}^{\prime}}=R_{\mathrm{s}} \overline{w^{\prime} \theta_{\mathrm{v}}^{\prime}}\right)_{\text {sat }}+\left(1-R_{\mathrm{s}}\right) \overline{w^{\prime} \theta_{\mathrm{v}}^{\prime}}\right)_{\text {unsat }} \text {. }
$$

The weighting $R_{\mathrm{s}}$ is determined through a partial condensation scheme, in which an estimate is made of the fraction of saturated states in the phase space of the semiconservative variables $\theta_{1}$ and $q_{1}$. The formulation assumes that all liquid water is instantly available to maintain saturation, which is not necessarily the case in unsaturated regions. The method has been described by Bougeault ( 1981 ). Here $R$, is found by integrating a normalized dimensionless variable in $\theta_{1}-q_{1}$ phase space that describes the distribution of states; its standard deviation is given by

$$
\sigma_{\mathrm{s}}=\frac{a}{2}\left(\overline{q_{1}^{\prime 2}}+\alpha_{1}^{2} \overline{\theta_{1}^{\prime 2}}-2 \alpha_{1} \overline{q_{1}^{\prime} \theta_{1}^{\prime}}\right)^{1 / 2}
$$

where

$$
a=\left(1+\frac{L_{\mathrm{v}} q_{\mathrm{s}}}{c_{\mathrm{p}} R_{\mathrm{v}} T_{\mathrm{1}}^{2}}\right)^{\prime} \quad \text { and } \quad \alpha_{1}=\frac{T}{\theta} \frac{L_{\mathrm{v}} q_{\mathrm{sl}}}{R_{\mathrm{v}} T_{1}^{2}} .
$$

To evaluate Eq. (B7) we use the relations from the 2.5 order closure model of Mellor and Yamada (1982), which simplify to

$$
\sigma_{s}^{2}=\frac{a^{2} B_{2} l}{4 \sqrt{2 E}} \frac{K}{\sigma_{\mathrm{h}}}\left(\frac{\partial q_{\mathrm{t}}}{\partial z}-\alpha_{1} \frac{\partial \theta_{1}}{\partial z}\right)^{2},
$$

where $l=c_{i / 4}^{3 / 4} E^{3 / 2} / \epsilon$ is the master mixing length, and $B_{2}=(2 / 3)\left(4 / c_{\mu}\right)^{3 / 4}$. For the probability distribution function, we use the exponential form given by Bougeault (1980). As discussed by Bougeault (1981), the exponential form differs from the Gaussian form only at extreme values (nearly 0 or 1 ) of the normalized dimensionless variable in $\theta_{1}-q_{1}$ phase space, and then only in a relative sense, as the absolute value of $R_{\mathrm{s}}$ is very nearly 0 or I either way. Such subtle differences in the probability distribution function make little difference to our model results.

\section{APPENDIX C}

\section{Surface Similarity Boundary Conditions}

Surface fluxes depend upon the drag coefficient $c_{\mathrm{d}}$ $=u_{*}^{2} / M^{2}$, in which the surface stress is defined by $u_{*}^{2}=\left[\left(\overline{w^{\prime} u^{\prime}}\right)^{2}+\left(\overline{w^{\prime} v^{\prime}}\right)_{s}^{2}\right]^{1 / 2}$. The mean wind speed in the lowest model layer is calculated by integrating a dimensionless stability-dependent wind speed profile:

$$
\phi_{\mathrm{m}}(z / L)=\frac{k z}{u_{*}} \frac{d M}{d z}
$$

where $k$ is von Kármán's constant and $L$ the Monin-Obukhov length:

$$
L=\frac{u_{*}^{3} \theta_{\mathrm{vs}}}{k g\left(\overline{w^{\prime} \theta_{\mathrm{v}}^{\prime}}\right)_{\mathrm{s}}}
$$

which is the ratio of surface shear production of $E$ to the surface buoyancy flux. The integration of the wind 
profile from $z_{0}$ (the aerodynamic roughness length) to $z$ yields

$$
\psi_{\mathrm{m}}=\int_{z_{*}, v^{\prime}}^{\phi_{\mathrm{m}}} \frac{M}{k z^{\prime}} d z^{\prime}=\frac{M}{u_{*}},
$$

thereby allowing the drag coefficient to be evaluated from $c_{\mathrm{u}}=\psi_{\mathrm{m}}^{2}$. Similarly, a transfer coefficient for transport of heat and vapor across the turbulent (constant flux ) sublayer is evaluated from $c_{\mathrm{h}}=\psi_{\mathrm{m}}^{-1} \psi_{\mathrm{h}}^{-1}$, in which $\psi_{\mathrm{h}}$ is an integrated dimensionless temperature profile. For the dimensionless profiles of wind speed and temperature, we follow Duynkerke (1988) and use the measurements of Dyer (1974). To evaluate the integrated profiles, we use the numerical method devised by Benoit ( 1977 ) for the unstable surface layer, which avoids numerical difficulties when approaching the neutral limit.

The acrodynamic roughness length is evaluated at the beginning of each time step from Charnock's (1955) relation:

$$
z_{0}=\frac{u_{*}^{2}}{g b_{c}}
$$

in which $b_{\mathrm{c}}{ }^{1}=0.015$. To iteratively calculate the surface fluxes within each time step, we first evaluate $\left(\overline{w^{\prime} \theta_{y}^{\prime}}\right)_{s}$ using the previous value of $c_{1}$ and the current values of $M, \theta(z)$, and $q_{v}\left(z_{x}\right)$. Then $L$ is evaluated, which allows a reevaluation of $c_{\mathrm{t}}$ and $c_{\mathrm{h}}$, followed by a recalculation of deposition velocities. Finally $\left(\overline{w^{\prime} \theta_{y}^{\prime}}\right)_{s}$ is reevaluated, and compared to its most recently calculated value. This loop iterates until the relative change in $\left(w^{\prime} \theta_{v}^{\prime}\right)$, falls below $10^{\circ}$.

\section{REFERENCES}

Ackerman. A. S. O. B. Toon, and P. V. Hobbs, 1993: Dissipation of marine stratiform clouds and collapse of the marine boundary layer due to depletion of cloud condensation nuclei by clouds. Science, 262, 226-229.

Akagawa, H., and K. Okada, 1993: Sizes of cloud droplets and cloud droplet residues near stratus cloud base. Atmos. Res, 30, 3749.

Albrecht, B. A.. 1989: Aerosols, cloud microphysics, and fractional cloudiness. Science, 245, $1227-1230$.

Anderson, G. P., S. A. Clough, F. X. Kneizys, J. H. Chetwynd, and E. P. Shettle, 1986: AFGL Atmospheric Constituent Profiles ( 0 $120 \mathrm{~km}$ ). AFGL-TR-86-0110, Air Force Geophysics Laboratory, Hanscom AFB. MA, 48 pp.

Baker, M. B., and R. J. Charlson. 1990: Bistability of CCN concentrations and thermodynamics in the cloud-topped boundary layer. Nature, 345, 142-145.

Barkstrom, B. R., 1978: Some effects of $8-12 \mu \mathrm{m}$ radiant energy transfer on the mass and heat budgets of cloud droplets. J. Atmos. Sci., 35, 665-673.

Beard, K. V., 1976: Terminal velocity and shape of cloud and precipitation drops aloft. J. Atmos. Sci., 33, 851-864

_- and H. T. Ochs III. 1984: Collection and coalescence efficiencies for accretion. J. Geophys. Res., 89, 7165-7169.

$\ldots$. and -_. 1993: Warm-rain initiation: An overview of microphysical mechanisms. J. Appl. Meteor, 32, 608-625.

Benoit, R., 1977: On the integral of the surface layer protile-gradient functions. J. Appl. Meteor., 16, 859-860.
Bougeault, P., 1981: Modeling the trade-wind cumulus boundary layer. Part I: Testing the ensemble cloud relations against numerical data. J. Atmos. Sici, 38, 2414-2428.

1985: The diurnal cycle of the marine stratocumulus layer: $A$ higher-order model study. J. Atmos. Sici, 42, 2826-2843.

Businger. J. A., J. C. Wyngaard, Y. Izumi, and E. F. Bradley, 1971: Flux-profile relationships in the atmospheric surface layer. $J$. Atmos. Sci., 28, $181-189$.

Caughey, S. J., and M. Kitchen, 1984: Simultaneous measurements of the turbulent and microphysical structure of nocturnal stratocumulus cloud. Quart. J. Roy. Meteor. Soc., 110, 1.3-34.

Charnock, H., 1955: Wind stress on a water surface. Quart. J. Roy Meterer. Soc. 81, 6.39-640.

Chen, $C$, and W. R. Cotton, 1987: The physies of the marine stratocumulus-topped mixed layer. J. Atmos. Sici. 44, $2951-$ 2977.

Clarke. A. D., N. C. Ahiquist, and D. S. Covert. 1987: The Pacific marine aerosol: Evidence for natural acid sulfates. J. Geophys. Res., 92, 4179-4190.

Coakliy, J. A., Jr., R. I. Bernstein, and P. A. Durkes, 1987: Effeet of ship-track effluents on cloud reflectivity. Sicience, 237, 10201022 .

Conover, J. H.. 1966: Anomalous cloud lines. J. Armos. Sici, 23, 778 785.

Covert. D. S., 1988: North Pacific marine background acrosol: Average ammonium to sulfate molar ratio equals 1 . J. Gowhs. Re's. 93, 8455-8458

Davies, R., 1985: Response of cloud supersaturation to radiative forcing. $J$. Almos. Si $i .42,2820-2825$.

Davis, M. H., 1972: Collisions of small droplets: Gas kinetic effects J. Atmos. Sci. 29,911-915.

Deardorff, J. W., 1980: Stratocumulus-capped mixed layers derived from a three-dimensional model. Beund-Layer Meteror. 18. $495-527$.

Downing, H. D., and D. Williams, 1975: Optical constants of water in the infrared. J. Geophys. Res., 80, 1656-1661.

Duynkerke, P. G., 1988: Application of the $E$-e turbulence closure model to the neutral and stable atmospheric boundary layer. $J$. Atmos. Sci. 45, $865-880$.

- and A. G. M. Driedonks, 1987: A model for the turbulent structure of the stratocumulus-topped atmospheric boundary layer. $J$. Atmos. $S \cdot i ., 44,43-64$.

$\ldots$ and $\ldots \ldots$.... 1988: The turbulent structure of a shear-driven stratus-topped atmospheric boundary layer. A comparison of model results with observations. J. Almos. Sci. 45, 2343-2351.

Dyer. A. J.. 1974: A review of flux-profile relationships. Bound. Laver Meteor. 7, 363-372.

Flossman, A. I., W. D. Hall, and H. R. Pruppacher, 1985: A theoretical study of the wet removal of atmospheric pollutants. Part I: The redistribution of aerosol particles captured through nucleation and impaction scavenging by growing cloud drops. $J$. Atmos. Sici., 42, 583-606.

Fuchs, N. A., 1964: The Mechanics of Aerosols. Pergammon, 408 pp.

Giorgi, F., 1986: A particle dry-deposition parameterization scheme for use in tracer transport models. J. Geophys. Res., 91, 9794 9806.

Hall, W. D., 1980: A detailed microphysical model within a twodimensional dynamic framework: Model description and preliminary results. J. Atmos. Sci, 37, 2486-2507.

Holtslag, A. A. M., and C. N. Moeg, 1991: Eddy diffusivity and countergradient transport in the convective atmospheric bound ary layer. $J$. Atmos. Sci., 48, 1690-1698.

Hudson, J. G., 1983: Effects of CCN concentrations on stratus clouds. J. Aimos, Sci., 40, 480-486.

, and P. R. Frisbie, 1991 : Cloud condensation nuclei near marine stratus. J. Geophys. Re's., 96, 20 795-20808.

King, M. D., L. F. Radke, and P. V. Hobbs, 1993: Optical properties of marine stratocumulus clouds modified by ships. $J$. Geophys. Res. 98, 2729-2739. 
Klett, J. D., and M. H. Davis, 1973: Theoretical collision efficiencies of cloud droplets at small Reynolds numbers. J. Atmos. Si i., 30 , $107-117$.

Kogan, Y. L., D. K. Lilly, Z. N. Kogan, and V. V. Filyushkin, 1994: The effect of $\mathrm{CCN}$ regeneration on the evolution of stratocumulus cloud layers. Atmos. Re's., 33, 137-150.

Lilly, D. K.. 1968: Models of cloud-topped mixed layers under a strong inversion. Quart. J. Roy. Mo'teor. Soc., 94, 292-309.

Mellor, G. L., and T. Yamada, 1982: Development of a turbulence closure model for geophysical fluid problems. Rev. Geophys. Space Phys., 20, 851-875.

Moeng, C.-H.. 1986: Large-eddy simulation of a stratus-topped houndary layer. Part I: Structure and budgets. J. Atmos. Sci., 43, $2886-2990$.

- and A. Arakawa, 1980: A numerical study of a marine subtropical stratus cloud layer and its stability. J. Atmos. Sci., 37, $2661-2676$.

Nicholls, S.. 1984: The dynamics of stratocumulus: Aircraft observations and comparisons with a mixed layer model Quart. J. Roy. Meteor. Soc., 110, 783-820.

1987: A model of drizzle growth in warm, turbulent, stratiform clouds. Quart. J. Roy. Meteor. Soc., 113, 1141-1170.

- and J. Leighton, 1986: An observational study of the structure of stratiform cloud sheets: Part I. Structure. Quart. J. Roy. Meteor. $S o c ., 112,431-460$.

NOAA. 1976: U.S. Standard Atmosphere. NOAA-S/T 76-1562. Washington, D.C., 227 pp.

Noonkester, V. R., 1984: Droplet spectra observed in marine stratus layers. J. Atmos. Sci., 41, 829-845.

O'Dowd, C. D., and M. H. Smith. 199.3: Physiochemical properties of aerosols over the northeast Atlantic: Evidence for windspeed-related submicron sea-salt aerosol production. J. Geophys. Res., 98, 11.37-1149.

Painter, L. R., R. D. Birkhoff, and E. T. Arakawa, 1969: Optical measurements of liquid water in the vacuum ultraviolet. $J$. Chem. Phys., 51, 243-251.

Palmer, K. F., and D. Williams, 1974: Optical properties of water in the near infrared. J. Opt. Soc. Amer., 64, 1107-1110.

Pruppacher, H. R., and J. D. Klett, 1978: Microphysics of Clouds and Precipitation. Reidel, 714 pp.
Radke, L. F., J. A. Cuakley Jr., and M. D. King, 1989: Direct and remote sensing observations of the effects of ships on clouds. Science, 246, $1146-1149$.

Randall, D. A.. J. A Coakley, C, W. Fairall, R. A. Kropfli, and D. H. Lenschow. 1984: Outlook for research on subtropical marine stratiform clouds. Bull. Amer. Meteor. Soc., 65, 1290-1301.

Slingo, A. R. Brown, and C. L. Wrench, 1982: A tield study of nocturnal stratocumulus; III. High resolution radiative and microphysical observations. Quart. J. Roy. Meteor. Soc., 108, $145-$ 165 .

Stull, R. B., 1988: An Introduction to Boundary Layer Meteorology. Kluwer, $666 \mathrm{pp}$

Toon, O. B., R. P. Turco, D. Westphal, R. Malone, and M. S. Liu, 1988: A multidimensional model for aerosols: Description of computational analogs. J. Aimos. Sci., 45, 2123-2143.

_. C. P. M.Kay, and T. P. Ackerman, 1989a: Rapid calculation of radiative heating rates and photodissociation rates in inhomogeneous multiple scaltering atmospheres. J. Geophys. Res., 94. $16287-1630 !$.

_, R. P. Turco, J. Jordan, J. Goodman, and G. Ferry, 1989b: Physical processes in polar stratospheric ice clouds. J. Geophys. Res., 94, $11359-11381$.

Tucker, G. B. and R. G. Barry, 1984: Climate of the North Atlantic Ocean. Climate's of the Oceans, H. van Loon, Ed., Elsevier, $716 \mathrm{pp}$.

Turco, R. P., P. Hamill, O. B. Toon, R. C. Whitten, and C. S. Kiang, 1979: The NASA-Ames Research Center stratospheric aerosol model. Part I Physical processes and computational analogs. NASA TP 1362 iii-94. (Available from NTIS. Springfield, VA 22161)

Turton, J. D., and S. Nicholls, 1987: A study of the diurnal variation of stratocumulus using a multiple mixed layer model. Quart. $J$. Roy. Meteor. Soc., 113, 969-1009.

Twomey, S. M. Piepgrass, and T. L. Wolfe, 1984: An assessment of the impact of pollution on global cloud albedo. Tellus, 36, 356366.

Warren, S. G., C. J. Hahn, J. London, R. M. Chervin, and R. L. Jenne, 1988: Global distribution of total cloud cover and cloud type amounts over the ocean. NCAR/TN $317+$ STR. NCAR, Boulder, $\mathrm{CO}, 212 \mathrm{pp}$

Woodcock, A. H. 1953: Salt nuclei in marine air as a function of altitude and wind force. J. Meteror. 10, 362-371. 